\title{
CRIMINALIDADE E EFEITO DETERRENCE NO BRASIL
}

\section{PEDRO RODRIGUES OLIVEIRA}

Graduando em Ciências Econômicas pela Universidade Federal de Viçosa (UFV).

País: Brasil Estado: São Paulo Cidade: Barbosa

Email de contato: pedro.r.oliveira@ufv.br ORCID: https://orcid.org/0000-0001-6630-9666

\section{STÉFFANY COSTA JARDIM}

Graduanda em Ciências Econômicas pela Universidade Federal de Viçosa, bolsista de Iniciação Científica pelo CNPq e aluna pesquisadora vinculada ao CNPq.

País: Brasil Estado: Minas Gerais Cidade: Viçosa

Email de contato: steffany.jardim@ufv.br ORCID: https://orcid.org/0000-0002-7561-6606

\section{EVANDRO CAMARGOS TEIXEIRA}

Possui doutorado em Economia Aplicada pela ESALQ/USP, mestrado em Desenvolvimento Econômico pela Universidade Federal do Paraná (UFPR) e graduação em Economia pela Universidade Federal de Juiz de Fora (UFJF). Atualmente, é Professor Associado I do Departamento de Economia da UFV e trabalha com Desenvolvimento Econômico, particularmente com os seguintes temas: criminalidade, saúde, educação e pobreza.

País: Brasil Estado: Minas Gerais Cidade: Viçosa

Email de contato: evandro.camargos@gmail.com ORCID: https://orcid.org./0000-0002-6470-2103

\section{Contribuição de cada autor:}

Pedro Rodrigues Oliveira e Stéffany Costa Jardim: responsáveis pelas estimações econométricas e análise dos resultados; Evandro Camargos Teixeira: responsável pela elaboração do artigo.

\section{RESUMO}

Diante das exorbitantes taxas de criminalidade verificadas principalmente nos países em desenvolvimento, um dos fatores mais importantes e capazes de impedir sua evolução se refere ao efeito deterrence. Este corresponde a existência de elementos dissuasórios que agem no sentido de desestimular o avanço do crime, com destaque para aqueles relacionados aos mecanismos da justiça e da polícia, denotados por Becker (1968). Dessa forma, este estudo inova ao considerar tais mecanismos em conjunto, representados pelos gastos públicos per capita com o sistema judiciário e o policiamento, respectivamente, e seus efeitos sobre as taxas de homicídios no Brasil durante o período 2005-2013. Para tal, utilizou-se um painel dinâmico, onde os resultados demonstram que apenas os gastos per capita com justiça impactam sobre a criminalidade, mas de forma positiva, o que levanta questionamentos a respeito da capacidade alocativa dos recursos públicos no intuito de deter o avanço do crime no país.

Palavras-chave: Criminalidade. Deterrence. Painel dinâmico.

\section{ABSTRACT CRIMINALITY AND DETERRENCE EFFECT IN BRAZIL}

In view of the exorbitant crime rates observed mainly in developing countries, one of the most important factors capable of preventing its evolution refers to the deterrence effect. This corresponds to the existence of dissuasive elements, which act to discourage the advance of crime, with emphasis on those related to the 
mechanisms of justice and police, denoted by Becker (1968). Thus, this study innovates when considering these mechanisms together, represented by public spending per capita with the justice system and policing, respectively, and their effects on homicide rates in Brazil during the period 2005-2013. To this end, a dynamic panel was used, where the results demonstrate that only the per capita spending on justice has an impact on crime, but in a positive way, which raises questions about the allocation capacity of public resources in order to stop the progress crime in the country.

Keywords: Criminality. Deterrence. Dynamic panel.

Data de recebimento: 19/02/2020 - Data de aprovação: 10/12/2020

DOI: $10.31060 /$ rbsp.2021.v15.n2.1263

\section{INTRODUÇÃO}

Em todo mundo, o avanço da criminalidade suscita elevada preocupação por parte da sociedade, particularmente dos formuladores de políticas públicas. No caso brasileiro, a situação não é diferente. Segundo o Atlas da Violência de 2019 (IPEA; FBSP, 2019), no ano de 2017, o país contabilizou a ocorrência de 65.602 homicídios, ou 31,6 casos por 100 mil habitantes. O Estado do Rio Grande do Norte apresentou a maior taxa, com 62,8 homicídios por 100 mil habitantes, ajudando a explicar o fato da Organização Mundial da Saúde (OMS) classificar o Brasil como o 9º país mais violento do mundo em 2017.

Para combater o avanço do crime, o governo necessita despender significativas cifras em segurança pública, subdivididas nos gastos com o sistema judiciário e o policiamento; e com encarceramento. Como exemplo, segundo Cerqueira (2017), os gastos com policiamento no Brasil em 2015 totalizaram 88 bilhões de reais, enquanto os gastos com o sistema prisional corresponderam a 14 bilhões de reais. No entanto, em 2016, o número de homicídios no Brasil cresceu 5,8\% em relação ao ano anterior, de acordo com dados do Atlas da Violência 2018 (IPEA; FBSP, 2018), mais que compensando o crescimento populacional de $0,8 \%$. Tais evidências provocam reflexões a respeito do efeito que os recursos dispendidos no combate à criminalidade possuem sobre as variações das ocorrências de crimes.

Nesse sentido, os gastos públicos podem diminuir a criminalidade sob alguns âmbitos, agindo sobre seus determinantes socioeconômicos ao promover políticas de incapacitação ou de dissuasão. De acordo com Cerqueira e Lobão (2003), os referidos gastos promovem maior nível de emprego, renda, educação, saúde, formalidade no mercado de trabalho, além de redução das desigualdades, dentre outros efeitos. No que concerne o efeito dos gastos públicos sobre as políticas de incapacitação, Chalfin e McCrary (2017) afirmam que eles se referem às ações que objetivam retirar indivíduos infratores de circulação, ou seja, medidas de encarceramento.

Comparando-se os efeitos dos gastos públicos, os impactos sobre os determinantes socioeconômicos da criminalidade apresentam resultados mais robustos no longo prazo, enquanto as políticas de encarceramento podem não ser eficazes, uma vez que a taxa de reincidência criminal no Brasil chega a 24,4\% (IPEA, 2015).

Mecanismos como os gastos públicos e as políticas com intuito de desestimularem atos criminosos geram o denominado efeito deterrence, que corresponde a elementos dissuasórios do comportamento criminoso. Segundo Becker (1968), o efeito deterrence eleva os custos de se optar pela atividade criminosa, 
dissuadindo os indivíduos em prosseguir na referida atividade e tendo como parâmetros a qualidade da justiça e da polícia.

Na literatura relativa ao tema, não há consenso a respeito do efeito deterrence sobre os crimes, sobretudo quando a variável utilizada corresponde aos gastos com segurança pública. Alguns estudos validam seu efeito negativo; outros, denotam associação positiva (em função de sua relação endógena com o crime); e ainda há aqueles que reportam efeito não significativo, a depender da escolha da proxy, da localidade do estudo e do nível de subnotificação referente aos crimes analisados.

Nesse sentido, autores como Kume (2004) e Mendonça, Sachsida e Loureiro (2003) encontram a não significância dos coeficientes de gastos públicos com segurança sobre a criminalidade, enquanto Cerqueira e Lobão (2003) e Becker e Kassouf (2017) verificaram relação negativa, que vai ao encontro do resultado esperado segundo a teoria econômica do crime de Becker (1968). Por outro lado, existem ainda trabalhos, como o de Gould, Weinberg e Mustard (2002), que denotaram relação positiva entre os gastos com segurança pública e a criminalidade, que será melhor analisada na seção seguinte.

Levando em consideração os aspectos mencionados, o presente estudo tem como objetivo analisar o impacto do efeito deterrence, representado pelos gastos públicos em segurança, subdivididos em justiça e policiamento, ambos per capita, sobre as taxas de homicídios no Brasil entre os anos de 2005 e 2013. Os gastos com justiça e policiamento configuram investimentos em segurança dispendidos pelos Estados em seu orçamento anual. Assim, o trabalho contribui na literatura ao considerar dois fatores relevantes em conjunto, proxies para o bom funcionamento da polícia e da justiça, que podem impactar a probabilidade de apreensão e/ou punição dos criminosos, presentes no artigo seminal de Becker (1968). Para tal, o estudo está dividido em mais cinco seções, além desta introdução. Na segunda seção, é apresentado o referencial teórico utilizado e, posteriormente, a terceira seção aborda a revisão de literatura relativa ao tema. A quarta seção traz a metodologia e em seguida são apresentados os resultados. Por fim, na sexta seção, são apresentadas as considerações finais.

\section{REFERENCIAL TEÓRICO}

Os estudos econômicos passaram a ter a criminalidade como problemática de pesquisa a partir do artigo seminal Crime and Punishment: An Economic Approach, de Gary Becker (1968), onde o autor elabora um modelo do comportamento do criminoso, tendo como base a racionalidade dos indivíduos. Segundo Becker (1968), o indivíduo compara custos e benefícios de se cometer a atividade ilegal dentro de alguns cenários. Mais especificamente, o indivíduo irá maximizar sua utilidade de forma a obter o maior benefício ao menor custo possível, através de três possíveis cenários: i) utilidade associada a não cometer o crime $\left(U_{n}\right)$; ii) utilidade relacionada a cometer crime e não incorrer em apreensão $\left(U_{1}\right)$; iii) utilidade associada a cometer crime e resultar em apreensão e punição $\left(U_{2}\right)$.

O modelo aponta que o indivíduo só irá cometer o crime se a soma das duas últimas utilidades for superior à utilidade de não cometer o crime. Formalmente, tem-se:

$$
(1-\rho) U_{1}+\rho U_{2}>U_{n}
$$

em que $\rho$ denota a probabilidade de ser apreendido e punido. 
Para Becker (1968), os crimes são mais atrativos quando a desutilidade da apreensão for menor e são menos atrativos quando a utilidade do mercado de trabalho legal for maior. Além disso, o autor observa que existe um prejuízo social causado pela oferta agregada de crimes. Esse prejuízo é captado pela equação (2):

$$
\begin{aligned}
& H i=H i(O i) \\
& \text { Com } H^{\prime} i=\frac{d H i}{d O i}>0
\end{aligned}
$$

em que $H i$ representa o prejuízo ocorrido em função da atividade criminosa e $O i$ representa o nível da atividade criminosa, mensurado pelo número de crimes.

Ao mesmo tempo, o autor afirma que o ganho obtido com a prática criminosa sofre acréscimos cada vez que um novo crime é cometido, como mostra a equação (3):

$$
\begin{aligned}
& G=G(O) \\
& \operatorname{Com} G^{\prime}=\frac{d G}{d o}>0
\end{aligned}
$$

O referido ganho obtido cada vez que um novo crime é praticado pode ser representado como um recurso monetário, quando o indivíduo é pago para exercer tal atividade ou quando ele o obtém diretamente ao realizar algum crime contra o patrimônio ou de sonegação fiscal, por exemplo. No entanto, também pode ser considerado como um ganho subjetivo no sentido de o indivíduo obter satisfação ao realizar determinada prática criminosa ou quando ele observa que não foi punido por cometer o ato ilícito.

Dessa forma, o dano para a sociedade pode ser captado pela diferença entre o prejuízo e o ganho, que é apresentado da seguinte forma:

$$
D(O)=H(O)-G(O)
$$

Como mencionado anteriormente, o indivíduo comete crime quando a utilidade no mercado do crime é maior do que no mercado de trabalho formal. Uma vez que os custos são menores que os benefícios e que as probabilidades de apreensão e punição são baixas ou quase nulas, o indivíduo verifica que cometer o ato criminoso compensa. Ademais, tem-se que a recompensa no mercado do crime pode ser observada em um menor período de tempo com relação ao mercado de trabalho legal. Essa análise pode ser representada pela equação (5):

$$
O_{j}=O_{j}\left(p_{j}, f_{j}, u_{j}\right)
$$

em que $O_{j}$ representa o número de crimes cometidos pelo indivíduo $j$ em determinado período de tempo; $p_{j}$, a probabilidade de condenação; $f_{j}$, a punição em caso de condenação e $u_{j}$ capta todas as outras demais variáveis que teriam influência na oferta de crimes.

Becker (1968) ainda argumenta que devido ao fato da apreensão e da punição estarem sob custódia do governo, este teria como influenciar na oferta agregada de crimes em determinada sociedade. Esta capacidade seria verificada pelo efeito deterrence que, como definido anteriormente, se refere a mecanismos que desincentivam o indivíduo a optar pelo crime, uma vez que pode modificar as 
probabilidades de apreensão e condenação, assim como a severidade da punição, caso o criminoso seja apreendido. Logo, ao aumentar a probabilidade de apreensão e a condenação e/ou a severidade da punição, a utilidade esperada de se cometer o crime seria reduzida, o que tenderia a resultar em redução na oferta agregada de crimes. Além disso, a elevação nos rendimentos no mercado de trabalho legal ou a elevação no nível de escolaridade aumentariam a utilidade de não se cometer crimes e tenderiam a reduzir o nível de criminalidade.

Referente à probabilidade de apreensão, condenação e severidade da punição, Becker (1968) afirma que esta estaria relacionada aos gastos com policiamento, justiça, equipe técnica e equipamentos especializados para realizar as ações. Todos esses mecanismos de deterrence incorreriam em custos para a sociedade, como mostra a equação (6):

$$
f^{\prime} \equiv b f \quad(6)
$$

sendo $f^{\prime}$ o custo social; $b$ um coeficiente que transforma $f$ em $f^{\prime}$ e modifica de acordo com tipo de punição, sendo $b \cong 0$ para multas e $b>1$ para outros tipos de punição.

A situação ótima do modelo seria aquela que permitisse a redução da criminalidade através do aumento nos parâmetros $p$ e $f$. Ademais, Becker (1968) aponta que a probabilidade de apreensão é mais efetiva se, e apenas se, os indivíduos forem propensos ao risco. Por sua vez, se os indivíduos forem avessos ao risco, um aumento na severidade da punição é mais efetivo do que na probabilidade de apreensão. Já no caso em que os indivíduos são neutros ao risco, os mecanismos são efetivos da mesma forma.

A partir do que foi exposto, observa-se que com o aumento dos danos sociais resultantes da atividade criminosa, haverá maior demanda da sociedade por mecanismos de proteção e combate a tal prática. Essas medidas para prevenir e/ou combater a atividade criminosa podem ser tomadas tanto a nível individual quanto social (através do governo). Nesse caso, por exemplo, tem-se o aumento dos gastos com seguros e sistemas de segurança privados por parte dos indivíduos e a elevação dos gastos com segurança pública pelo governo.

Levando-se em consideração a análise realizada no presente estudo, será possível observar se a elevação dos dispêndios com segurança pública nas unidades federativas brasileiras tem diminuído as taxas de homicídios, ou seja, se os mecanismos à disposição do governo estão dissuadindo os indivíduos a exercerem atividade criminosa.

\section{REVISÃO DE LITERATURA}

A partir do supracitado trabalho seminal de Becker (1968), vários estudos foram realizados a fim de verificar se existem fatores à disposição do governo que poderiam impactar na utilidade esperada do indivíduo em praticar crimes, de modo a desincentivar a atividade criminal. Como já especificado, esse mecanismo é conhecido na literatura como efeito deterrence e pode ser expresso através de diversas proxies, entre elas o efetivo policial, os gastos com segurança pública, as taxas de encarceramento, entre outras. Esses fatores impactariam diretamente a probabilidade de apreensão e de punição do indivíduo.

Boa parte da literatura, principalmente internacional, tem estimado as elasticidades do crime em relação ao número de policiais, sendo estas mais elevadas para crimes violentos em relação àqueles contra o 
patrimônio, como disposto por Wolpin (1978), Entorf e Spengler (2000), Cherry e List (2002) e Saridakis (2004). Nesse sentido, Suliano e Oliveira (2010) verificaram que o aumento do efetivo policial ${ }^{1}$ tende a impedir a ocorrência de crimes contra o patrimônio, mensurados pelas taxas de furtos e roubos no Estado do Ceará. Os autores argumentaram que a maior quantidade de policiais tende a inibir a ação dos criminosos, reduzindo seus benefícios e aumentando os custos da atividade criminal.

Existe grande atenção na literatura com a utilização da referida variável de efetivo policial, porque caso a contratação de policiais anteceda o aumento no número de crimes, poderá haver viés positivo de seletividade. Sendo assim, autores como Levitt (2002) utilizam variáveis instrumentais para realizar a estimação e controlar esse viés. Nesse caso, os resultados apontados pelo autor demonstram que no ano anterior às eleições estaduais e municipais espanholas o número de policiais tendia a aumentar, dada a intenção dos políticos em se mostrarem preocupados com o combate ao crime.

Outra análise dos estudos relativos ao efeito deterrence é verificada através do impacto da alteração do efetivo policial sobre as taxas de crimes, mas considerando uma abordagem diferente da convencional: a intensificação policial em pontos estratégicos, ou seja, em áreas em que ocorre maior quantidade de crimes. O primeiro estudo nesse sentido foi realizado por Sherman e Weisburd (1995), que testaram a intensificação da força policial em áreas relevantes para redução da criminalidade. Os autores verificaram diminuição de aproximadamente $10 \%$ nas taxas de crimes para o grupo tratado em relação ao grupo de controle. Adicionalmente, não encontraram evidências de deslocamento do crime para regiões adjacentes.

Nesta mesma linha, Kleck e Barnes (2014) investigaram se o aumento no número de policiais per capita e na taxa de encarceramento exercem efeito deterrence sobre as ocorrências de homicídio, roubo, assalto e furto nos EUA. Os autores apontaram que o nível de policiamento não parece produzir maior percepção legal de risco pelos indivíduos. Isso não significa que os criminosos não tenham consciência do risco, mas que a força policial, em termos de número de policiais per capita, e a taxa atual de prisão não têm capacidade de afetar essa percepção. Isso pode levar os formuladores de política a repensarem se o aumento na força policial traz benefícios suficientes sobre a redução de crimes para compensar o custo incorrido, dada a inobservância do efeito deterrence.

Piliavin et al. (1986) discorrem sobre outra proxy relevante de deterrence, que consiste nos fatores utilizados pela sociedade para inferir conformidade entre seus membros, sendo de controle interno (onde os indivíduos são incutidos com valores, normas e atitudes convencionais da sociedade) e de controle externo (fatores que ameaçam, coagem ou sancionam uma pessoa em direção à conformidade).

Particularmente, em relação aos fatores de controle externo, os autores analisaram os efeitos de sanções formais sobre o comportamento criminoso dos indivíduos sob a forma de dois tipos de riscos, o "risco formal" (que compreende a probabilidade de ser visto ao cometer um crime, ser delatado, ser preso e perder o emprego) e o "risco pessoal" (perder um cônjuge ou um amigo devido à prisão). Os autores encontraram resultados que corroboram a teoria de Becker (1968), pois comprovou-se que indivíduos que possuem expectativas de auferirem maiores ganhos monetários no mercado ilegal têm maior probabilidade de desobedecerem a lei. Entretanto, um importante e contraintuitivo resultado foi observado com relação às variáveis de deterrence. O modelo estimado demonstrou que tanto o

1 Resultado semelhante é encontrado por Corman e Mocan (2000), os quais constatam que o efetivo policial se relaciona negativamente com os crimes de roubos e arrombamentos. Os autores demonstram ainda que quanto menor o período analisado, maior a influência do efeito deterrence sobre as taxas de crimes. 
risco formal quanto o risco pessoal de punição não possuem efeito no comportamento do criminoso. Como explicação, os autores denotam a possibilidade das variáveis de deterrence não se relacionarem linearmente com o ato criminoso, configurando má especificação da forma funcional do modelo.

Entre os diversos estudos que analisam o efeito deterrence sobre a criminalidade, existem também aqueles que abordam a importância da percepção de risco por parte dos indivíduos. Alguns autores afirmam que se a percepção de risco se aproxima do risco real, mudanças nas políticas de segurança poderiam ser utilizadas como mecanismo de deterrence. Nesse sentido, Anwar e Loughran (2011) verificam relação positiva entre prisão e maior percepção em relação ao risco de ser apreendido. Especificamente, os autores concluíram que a associação é mais forte no início da carreira do criminoso, tendendo a se dissipar ao longo da vida do mesmo.

A literatura analisa o efeito deterrence não apenas através da força policial, mas também em relação à severidade da punição, sendo utilizada comumente a taxa de encarceramento como proxy nos trabalhos realizados. Nesse sentido, Johnson e Raphael (2012) encontraram para os EUA uma elasticidade de 0,1 p.p para crimes violentos e 0,2 p.p. para crimes contra o patrimônio em relação à taxa de encarceramento. $O$ estudo de Corman e Mocan (2000) converge com essa análise ao verificar para a cidade de Nova lorque, nos EUA, que os crimes de assassinato, arrombamento e roubo de veículos declinam conforme aumenta o número de prisões.

Bell, Jaitman e Machin (2014) encontram resultados semelhantes a respeito da severidade da punição e ponderam ainda que a evidência empírica persuasiva para essa questão é difícil, pois, pelo menos em parte, o endurecimento da sentença não ocorre aleatoriamente, mas como resposta a um aumento da ocorrência de determinados crimes.

Assim, os autores analisaram o efeito da rapidez e do endurecimento de sentenças para os indivíduos envolvidos em crimes relacionados a motins (roubo, dano ao patrimônio e crimes contra a pessoa) na cidade de Londres, na Inglaterra, tendo como foco regiões que previamente não estavam sofrendo aumentos diferenciais nos crimes. Desse modo, o endurecimento das sentenças não era algo previsto pelos agentes, o que pode servir para verificar um possível efeito dissuasivo das sentenças pós-motim. Os resultados demonstraram um decrescimento significativo nos crimes associados ao motim, tanto em áreas acometidas pelo evento como naquelas que não o haviam vivenciado, seis meses após o ocorrido. Adicionalmente, encontraram pouca evidência de que o deslocamento espacial e o aumento do policiamento nas ruas tenham sido responsáveis por essa mudança, e observaram queda nos crimes em regiões distantes daquelas atingidas pelos motins, o que significa que os efeitos da incapacitação não explicam isoladamente a mudança, mas sim que houve um efeito deterrence geral, representado pela severidade da punição, o que afetou a percepção da população em relação aos riscos de punição.

Lee e McCrary (2017), entretanto, encontram resultados divergentes. Os autores discorrem sobre a existência do efeito deterrence no Estado norte-americano da Flórida, nos EUA, mensurado pela taxa de prisões sobre as ocorrências criminais, levando em consideração as faixas etárias dos infratores. Os autores verificaram que existe uma mudança na dinâmica das sentenças judiciais para infratores menores de idade e adultos, sendo os indivíduos maiores de dezoito anos $230 \%$ mais propensos a serem presos do que jovens menores de idade. Dada essa mudança nas probabilidades de prisão, os autores possuíam como hipótese uma descontinuidade na tendência da ocorrência de crimes quando os indivíduos completassem dezoito anos, isto é, uma maior suscetibilidade ao efeito deterrence quando se atinge a maioridade. 
Tal descontinuidade, entretanto, não foi observada de maneira significativa, sendo que a redução das ocorrências criminais foi de apenas $2 \%$ quando os indivíduos atingiram os dezoito anos de idade.

Sob outro enfoque, ao realizarem uma meta análise de estudos que abordam as estratégias de dissuasão do crime corporativo e de colarinho branco em quatro áreas (leis, sanções punitivas, política regulatória e tratamentos múltiplos), Schell-Busey et al. (2016) observaram que estratégias praticadas de forma isolada, com exceção da política regulatória, têm muito pouco ou nenhum impacto a níveis individual e corporativo. Entretanto, estudos que examinaram múltiplos tratamentos produziram significativo efeito deterrence a níveis individual e corporativo. Em relação aos múltiplos tratamentos, notou-se que o principal mecanismo que apresentou impacto sobre o comportamento das empresas foi a junção de monitoramento regulatório, inspeções e fiscalização.

Além das diversas vertentes apresentadas, os trabalhos que estudam a relação entre efeito deterrence e criminalidade utilizam ainda como proxies as variáveis de gastos com segurança pública, que englobam os gastos com policiamento e justiça, sobretudo na literatura econômica. Percebe-se que não existe consenso acerca dos efeitos de tais gastos sobre as taxas de crimes.

Kume (2004), ao analisar os determinantes da criminalidade no Brasil através de um painel dinâmico, observou que os gastos em segurança pública não se mostram significativos para a redução das taxas de crime, ao contrário daqueles referentes à educação, que contribuem para sua diminuição. O autor afirma que a não significância da referida variável pode ser explicada pela ineficiência na utilização dos recursos públicos. Esse resultado também é encontrado por Mendonça, Sachsida e Loureiro (2003) em um estudo para os Estados brasileiros no período de 1987 a 1995. Os autores justificam tal relação ao afirmarem que possivelmente o impacto negativo dessa variável somente ocorrerá no longo prazo. Ademais, o aumento esporádico dos gastos em segurança pública provavelmente terá efeitos reduzidos quando comparados a uma política contínua de segurança.

Como alguns trabalhos explicam a não significância associada à má alocação dos recursos públicos em segurança, é válido apresentar um estudo que analisa tal relação. Castanheira Júnior (2011) utilizou o método de Análise Envoltória de Dados para verificar quais Estados brasileiros seriam mais ou menos eficientes na alocação dos recursos em segurança pública entre 2005 e 2008. O autor observou que os gastos públicos em segurança estão relacionados à eficiência alocativa dos recursos, uma vez que no modelo geral e naquele com Estados ineficientes, a variável não foi significativa; por sua vez, no modelo com Estados eficientes, houve significância da variável e o sinal verificado foi negativo, como esperado.

Por outro lado, existem na literatura estudos que encontram relação significativa e negativa entre os gastos com segurança pública e a criminalidade, sendo um desses o de Cerqueira e Lobão (2003), que utilizaram séries temporais para os Estados do Rio de Janeiro e São Paulo. Os autores encontraram que o aumento nas despesas com segurança pública na tentativa de dissuadir os homicídios tem efeito negativo, mas limitado, para os dois Estados, sendo que para o Rio de Janeiro essa variável possui maior elasticidade, praticamente dobrando seu efeito no longo prazo.

Lins e Montes (2017) confirmam o referido efeito negativo, ao analisarem a relação entre os gastos municipais com segurança pública e a violência nos municípios fluminenses. Para a variável de segurança pública, os coeficientes estimados foram significativos e negativos, indicando a capacidade do gasto municipal em exercer o efeito dissuasório. 
Além dessas duas relações encontradas, ainda é presente na literatura a relação positiva entre os gastos públicos com segurança e a criminalidade, o que é justificado pela possível endogeneidade presente na relação, uma vez que os locais com maiores taxas de criminalidade são os que demandam mais recursos do Estado para combatê-la. Um exemplo é o trabalho de Gould, Weinberg e Mustard (2002), que em uma análise para os EUA entre 1979 e 1997, observaram relação positiva entre gastos com segurança e crime, tanto para os crimes contra patrimônio quanto para os crimes violentos.

Nesse sentido, Loureiro e Carvalho Júnior (2007) analisaram o impacto dos gastos em segurança pública e assistência social nos Estados brasileiros entre 2001 e 2003. Os autores verificaram, inicialmente, que os gastos com segurança têm impacto positivo e significativo sobre as taxas de crime no Brasil, entretanto, quando corrigido o problema da endogeneidade presente nessa relação, através da utilização de variáveis instrumentais, verificou-se elasticidade significativa negativa de tais gastos sobre a variável dependente.

Por fim, Leung (1995) critica a teoria econômica convencional que estuda o efeito deterrence, até aqui apresentada, pois, segundo o autor, os modelos dinâmicos, geralmente utilizados, ignoram a reincidência criminal. Sendo assim, o autor formula um modelo de deterrence geral e dinâmico, incorporando a reincidência criminal. Os resultados demonstram que o aumento na probabilidade ${ }^{2}$ de punição apresenta efeito deterrence mais elevado que a elevação na severidade da punição.

Assim, diante das divergências em relação aos resultados acima demonstradas, Braga, Weisburd e Turchan (2018) analisaram vinte e quatro experimentos onde foram implementadas políticas específicas de dissuasão de crimes, isto é, políticas problem-oriented de efeito deterrence. Os autores verificaram que de maneira geral (em 19 dos 24 casos estudados), o efeito deterrence foi capaz de reduzir a criminalidade de maneira significativa, mesmo que moderadamente. Tais resultados colocam em voga a necessidade de se estudar as políticas de dissuasão para assim inferir sobre seus reais efeitos sobre o crime.

\section{METODOLOGIA}

A presente seção se subdivide-se em três subseções. A primeira apresenta o modelo econométrico utilizado e a justificativa para utilização do mesmo; a segunda, os testes a serem utilizados para comprovar a robustez do modelo estimado; e a última apresenta as variáveis inseridas, bem como a fonte dos dados.

\section{ESPECIFICAÇÃO DO MODELO ECONOMÉTRICO}

O presente estudo utiliza o método de dados em painel para verificar a relação entre o efeito deterrencee as taxas de homicídios das unidades federativas brasileiras. O uso dessa metodologia permite a combinação entre dados cross-section com informações de séries temporais, ou seja, observa-se o comportamento de cada unidade federativa brasileira ao longo do tempo. Como consequência, têm-se vantagens em se utilizar este método em relação ao cross-section ou séries de tempo unicamente. Uma das vantagens é que a técnica de dados em painel permite levar em consideração os efeitos específicos de cada unidade, ou seja, controla a heterogeneidade presente na amostra (MACHADO; SACHSIDA; MENDONÇA, 2005).

2 Resultado semelhante em relação à probabilidade de detenção é encontrado por Lobo e Fernandez-Carrera (2005), em uma análise para o município de Salvador, no Estado da Bahia. 
Além disso, por observar repetidas observações em corte transversal, é possível examinar de forma mais adequada a dinâmica de mudança das variáveis de interesse.

O modelo de dados em painel pode ser estático ou dinâmico. No primeiro caso, ele pode ser utilizado de duas formas, que são estimadas a partir dos pressupostos considerados em relação à possível correlação entre o termo de erro e as variáveis explicativas, que são o modelo de efeitos fixos e de efeitos aleatórios.

De acordo com Vieira, Avellar e Veríssimo (2013), tanto o modelo de efeitos fixos quanto o de efeitos aleatórios apresentam a limitação de não lidarem com uma possível relação endógena entre algumas variáveis explicativas e a variável dependente. Este problema pode ser observado no presente estudo, uma vez que os níveis da criminalidade podem explicar os gastos com policiamento e justiça, ao mesmo tempo em que os referidos gastos podem impactar nas taxas de homicídios.

Além disso, a criminalidade apresenta uma característica inercial, ou seja, o número de crimes atual é influenciado pelo total de crimes do período anterior. Nesse caso, Santos (2009) atribui à inércia a aprendizagem, ou ainda, a especialização na atividade criminosa ao longo do tempo e a baixa probabilidade de insucesso no crime, particularmente no Brasil, devido à baixa probabilidade de denúncia, prisão, julgamento, condenação e efetiva punição.

Essas limitações podem ser solucionadas por meio da estimação do modelo com dados em painel dinâmico, desenvolvido por Arellano e Bond (1991), a partir das estimações do método de momentos generalizados (GMM). Nesse modelo, leva-se em consideração que a variável explicativa é endógena e considera-se como variável explicativa a própria variável dependente defasada. Formalmente, tem-se:

$$
y_{i, t}=\alpha y_{i, t-1}+\beta X_{i, t}+\varepsilon_{i, t}
$$

em que y representa o logaritmo da taxa de homicídios por 100 mil habitantes; $X$, o vetor de variáveis explicativas; e $\varepsilon$, o termo de erro. Os subscritos i e $t$ indicam, respectivamente, a unidade da federação e o período de tempo.

Ainda, assume-se que no termo de erro estão inclusos os efeitos específicos sobre as taxas de criminalidade de cada unidade da federação, $\mu_{i}$, e os choques aleatórios não observados ao longo do tempo, $v_{i, t}$.

$$
\varepsilon_{i, t}=\mu_{i}+v_{i, t}
$$

Dessa forma, o modelo dinâmico pode ser escrito da seguinte forma:

$$
y_{i, t}=\alpha y_{i, t-1}+\beta X_{i, t}+\mu_{i}+v_{i, t}
$$

Em que $\mu_{i} \sim \operatorname{IID}\left(0, \sigma_{\mu}^{2}\right)$ e $v_{i} \sim I I D\left(0, \sigma_{v}^{2}\right)$. Sendo os componentes $\mu_{i}$ os efeitos fixos individuais (de cada Estado) e as invariantes no tempo, enquanto $v_{i, t}$ são os choques aleatórios específicos a cada unidade da federação e que variam com o tempo, sendo heterocedásticos e correlacionados no tempo dentre os Estados, mas não entre os mesmos.

$$
\begin{gathered}
E\left(\mu_{i}\right)=E\left(v_{i t}\right)=E\left(\mu_{i} v_{i t}\right)=0 \\
E\left(v_{i t} v_{j s}\right)=0 \forall i, j, t, s \operatorname{com} i \neq j
\end{gathered}
$$


O método GMM elimina os efeitos fixos sobre a taxa de homicídios de cada Estado ao longo do tempo ao realizar uma transformação no momento de estimação do modelo. Isso significa que o modelo é estimado em sua primeira diferença para retirar os componentes que não variam com o tempo. Entretanto, mesmo com a transformação, verifica-se ainda um viés, pois a taxa de crime defasada $\Delta y_{i, t-1}$ e o termo de erro $\Delta v_{i, t}$ são correlacionados. Sendo assim, Arellano e Bond (1991) sugerem que se utilizem as variáveis defasadas em pelo menos dois períodos como variável instrumental para o modelo em primeiras diferenças, como segue:

$$
\Delta y_{i, t}=\alpha \Delta y_{i, t-1}+\beta \Delta X_{i, t}+\Delta v_{i, t}
$$

Adicionalmente, verifica-se na literatura ${ }^{3}$ que é possível aumentar o número de defasagens no intuito de melhorar a eficiência do estimador. Sendo assim, optou-se no presente trabalho por estimar o modelo com 2 a 4 defasagens dos instrumentos, a fim de garantir maior robustez ao mesmo.

\section{TESTES DE ESPECIFICAÇÃO}

Os testes comumente utilizados para modelos de painel dinâmico são o de Sargan e o de correlação serial. O primeiro teste indica a validade dos instrumentos, a falha em rejeitar a hipótese nula indica que os instrumentos são robustos; já o teste de correlação serial é realizado em primeira e segunda ordem sobre os resíduos em primeira diferença, $\Delta v_{i, t}$. Espera-se que os erros em primeira diferença sejam correlacionados em primeira ordem e não autocorrelacionados em segunda ordem (ARELLANO; BOND, 1991).

\section{DADOS E VARIÁVEIS}

As variáveis utilizadas no presente trabalho foram extraídas de diversos bancos de dados, entre eles a Pesquisa Nacional por Amostra de Domicílios (Pnad), realizada pelo Instituto Brasileiro de Geografia e Estatística (IBGE), e a do Fórum Brasileiro de Segurança Pública (FBSP). A variável dependente utilizada foi a taxa de homicídios por 100 mil habitantes e as explicativas foram inseridas com base na literatura. $O$ homicídio (art. 121) é um dos delitos previstos no Código Penal como crime contra a pessoa; além deste, tem-se o induzimento, a instigação ou o auxílio ao suicídio (art. 122), o infanticídio (art. 123) e o aborto (art. 124, 125, 126 e 128). Santos e Kassouf (2008) argumentam que na maior parte dos países a taxa de homicídios é a melhor medida disponível para mensurar a ocorrência de crimes, devido à elevada taxa de sub-registro das demais categorias. Sendo assim, utilizar a taxa de homicídios como variável dependente pode conferir uma análise mais acurada dos efeitos dos gastos com justiça e policiamento sobre esse crime nos Estados brasileiros.

Adicionalmente, outros crimes, além dos que atingem diretamente a vida humana, apresentam elevada subnotificação, como é o caso dos crimes contra patrimônio. A subnotificação implica em erro de medida nas taxas de crimes, o que pode levar a resultados viesados (SANTOS; KASSOUF, 2008). Como já salientado, no caso das taxas de homicídios, a subnotificação é muito menor por implicar em perda de vida humana.

Na Tabela 1, abaixo, são sumarizadas todas as variáveis utilizadas no modelo estimado, assim como suas descrições e fontes. A primeira variável explicativa utilizada foi educ, que representa a proporção

3 Ver Santos (2009) e Kume (2004). 
de indivíduos em relação à população economicamente ativa (PEA), que no período de análise possuía pelo menos o ensino médio completo. O efeito esperado desta é negativo, uma vez que a escolaridade é apontada na literatura como responsável por aumentar os custos de oportunidade de incursão na atividade criminosa ao contribuir para a elevação dos salários no mercado de trabalho formal, seguindo a teoria econômica do crime de Becker (1968). Além disso, a educação faz parte do processo de desenvolvimento moral do indivíduo, tendo importância na inclusão social do mesmo (TEIXEIRA, 2011).

A variável grau_urba representa o grau de urbanização das unidades federativas no período de 2005 a 2013. Para esta variável, a literatura não encontra consenso, haja vista que o grau de urbanização pode resultar em um sistema judicial mais desenvolvido (FURTADO, 2007), o que contribuiria para reduzir a criminalidade ao desestimular sua prática; e por outro lado, poderia promover e facilitar redes de interações entre criminosos, aumentando a aglomeração de pessoas que possam se tornar alvos atrativos (PEZZIN; MACEDO, 1987), o que resultaria em aumento da criminalidade.

Em relação à variável de renda (lrenda), existe ambiguidade na literatura, como aponta Santos (2009). Assim, observa-se efeito positivo da variável sobre os crimes em alguns trabalhos, o que é justificado pelo fato da mesma associar-se positivamente aos ganhos da criminalidade, principalmente daqueles com motivações econômicas; e em outros, é verificado efeito negativo por estar relacionada ao aumento dos custos de oportunidades do crime, quando se analisa os ganhos monetários no mercado formal de trabalho.

\section{TABELA 1}

\section{Variáveis utilizadas na estimação do modelo econométrico e suas fontes}

\begin{tabular}{|c|c|c|c|}
\hline Tipo de Variável & Variável & Descrição & Fonte \\
\hline Variável Dependente & taxa_hom & $\begin{array}{l}\text { Logaritmo da taxa de homicídios por } \\
\qquad 100 \text { mil habitantes }\end{array}$ & FBSP \\
\hline \multirow{5}{*}{$\begin{array}{l}\text { Variáveis Explicativas } \\
\text { (Controle) }\end{array}$} & fator inercial & $\begin{array}{c}\text { Taxa de homicídios defasada em um } \\
\text { período }\end{array}$ & FBSP \\
\hline & educ & $\begin{array}{l}\text { Proporção de pessoas em relação à PEA } \\
\text { que possuem pelo menos ensino médio } \\
\text { completo }\end{array}$ & IBGE \\
\hline & grau_urba & Taxa de urbanização dos Estados & IBGE \\
\hline & lrenda & $\begin{array}{l}\text { Logaritmo da renda per capita } \\
\text { deflacionada }\end{array}$ & IBGE \\
\hline & hom_jov_negro & $\begin{array}{c}\text { Proporção de homens jovens negros } \\
\text { entre } 15 \text { e } 24 \text { anos }\end{array}$ & IBGE \\
\hline \multirow{2}{*}{$\begin{array}{l}\text { Variáveis Explicativas } \\
\text { (Efeito Deterrence) }\end{array}$} & gasto_pol & $\begin{array}{c}\text { Gastos per capita com policiamento } \\
\text { deflacionados }\end{array}$ & FBSP \\
\hline & gasto_jus & $\begin{array}{c}\text { Gastos per capita com o judiciário } \\
\text { deflacionados }\end{array}$ & $\begin{array}{l}\text { Sistema de Coleta de } \\
\text { Dados Contábeis }\end{array}$ \\
\hline \multirow{2}{*}{ Variáveis Instrumentais } & taxa_mag & $\begin{array}{c}\text { Taxa de magistrados por } 100 \text { mil } \\
\text { habitantes }\end{array}$ & FBSP \\
\hline & taxa_analfa & Taxa de analfabetismo & IBGE \\
\hline
\end{tabular}


A variável hom_jov_negro representa a proporção de indivíduos do sexo masculino entre 15 e 24 anos negros. Essa relação foi constituída pelo fato de que os homens jovens negros são os que mais matam e morrem no Brasil ${ }^{4}$ e o efeito esperado é positivo, ou seja, quanto maior a proporção de indivíduos jovens e negros nas unidades federativas, maior a taxa de homicídios.

As duas variáveis explicativas que captam o efeito deterrence, gastos públicos per capita com sistema judiciário e policiamento, foram consideradas endógenas no modelo, uma vez que a literatura denota tal relação com a variável dependente - taxa de homicídios. Além dessas, foram utilizadas como variáveis instrumentais para controle da endogeneidade a taxa de analfabetismo dos Estados e a variável de deterrence de taxa de magistrados. Cabe ainda ressaltar que as variáveis referentes aos gastos públicos com o sistema judiciário e o policiamento, assim como a que denota o nível de renda, foram deflacionadas pelo Índice Nacional de Preços ao Consumidor Amplo (IPCA).

Por fim, a variável dependente foi utilizada também como variável explicativa, com a defasagem de 1 lag, a fim de captar o efeito inércia do crime, o que é um pressuposto do modelo dinâmico. Como apontado na seção anterior, vários estudos encontram que parte do crime passado é repassado para o período atual, devido à aprendizagem, à impunidade e a outros fatores.

\section{RESULTADOS}

Esta seção dedica-se a apresentar os principais resultados obtidos pela pesquisa. Para isso, subdividese em duas subseções: uma apresenta a análise descritiva das variáveis utilizadas no estudo, a outra, os resultados do modelo econométrico.

\section{ANÁLISE DESCRITIVA}

A Tabela 2 apresenta as estatísticas descritivas das variáveis utilizadas no modelo econométrico do presente estudo. A análise de tais estatísticas proporciona melhor compreensão da amostra utilizada, assim como ajuda a entender os resultados econométricos apresentados posteriormente.

\section{TABELA 2}

\section{Estatísticas descritivas}

\begin{tabular}{lrrrr}
\hline Variável & \multicolumn{1}{c}{ Média } & Desvio Padrão & Mínimo & Máximo \\
\hline gasto_pol & 90712.1300 & 333373.0000 & 0.1944 & 4568301.0000 \\
gasto_jus & 145.2980 & 104.1736 & 30.4500 & 768.0200 \\
educ & 25.9859 & 6.3681 & 11.5900 & 46.2700 \\
grau_urba & 79.6493 & 8.8972 & 61.1000 & 96.8000 \\
lrenda & 2328.2800 & 329.5514 & 569.0000 & 2580.0000 \\
hom_jov_negro & 4.0139 & 1.2432 & 0.8400 & 6.0900 \\
\hline
\end{tabular}

4 Ver Atlas da Violência (2017) e Santos (2009). 
Os Gráficos 1, 2 e 3 apresentam a evolução da taxa de homicídios, os gastos com o sistema judiciário e os gastos com policiamento por 100 mil habitantes, respectivamente, para o período 2005-2013; que são as variáveis mais relevantes do estudo. É possível perceber crescimento dos homicídios no país, com exceção do ano de 2012. Concomitantemente, os gastos por 100 mil habitantes com o sistema judiciário também aumentam de forma contínua ao longo do período, o que pode denotar relação endógena, a ser comprovada na próxima subseção. Já os gastos por 100 mil habitantes com policiamento também crescem ao longo do tempo, porém de maneira menos constante que os gastos com o sistema judiciário.

Ademais, nos Anexos 1, 2 e 3 são apresentadas as estatísticas descritivas das variáveis com menor nível de agregação, sendo possível visualizar as tendências individuais dos Estados.

\section{GRÁFICO 1}

\section{Evolução da taxa de homicídios no Brasil durante o período 2005-2013}

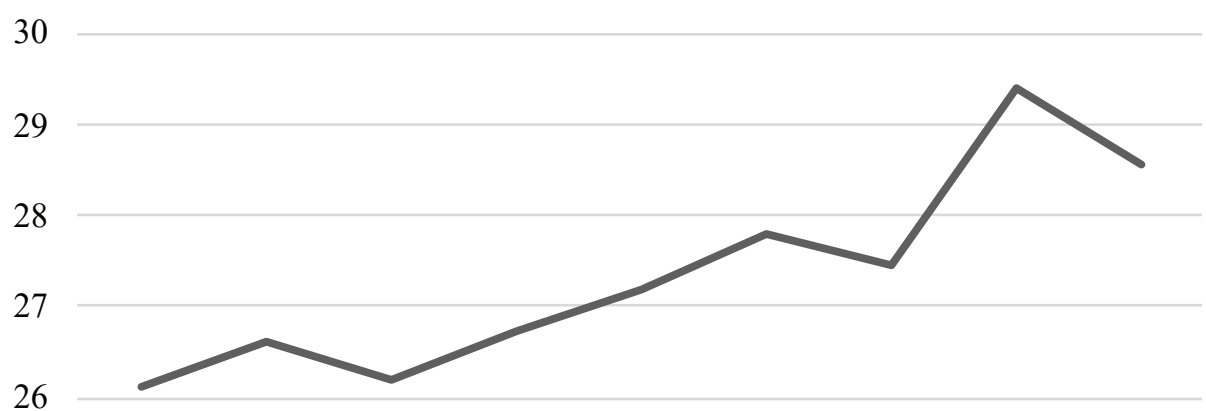

25

24

$\begin{array}{lllllllll}2005 & 2006 & 2007 & 2008 & 2009 & 2010 & 2011 & 2012 & 2013\end{array}$

\section{GRÁFICO 2}

\section{Evolução dos gastos com Justiça no Brasil durante o período 2005-2013}

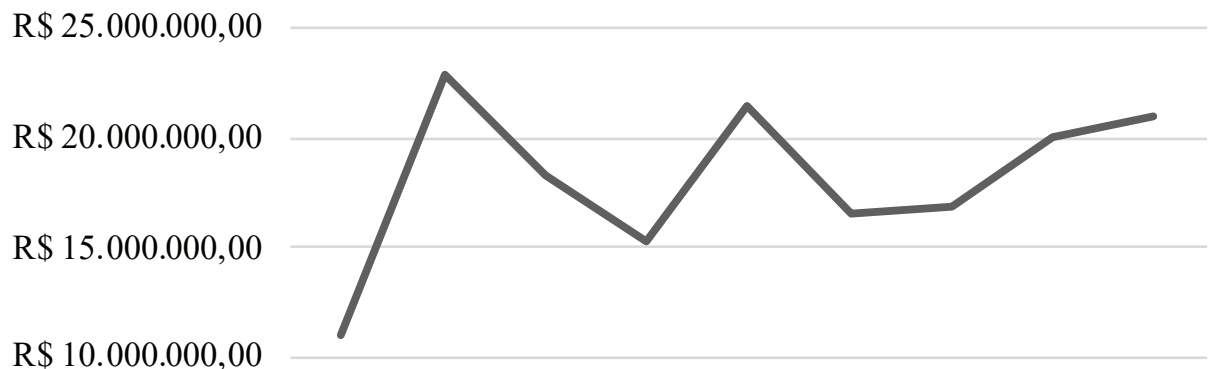

$\mathrm{R} \$ 5.000 .000,00$

$\mathrm{R} \$ 0,00$ 


\section{GRÁFICO 3}

\section{Evolução dos gastos com Policiamento no Brasil durante o período 2005-2013}

$\mathrm{R} \$ 12.000 .000,00$

$\mathrm{R} \$ 10.000 .000,00$

$\mathrm{R} \$ 8.000 .000,00$

$\mathrm{R} \$ 6.000 .000,00$

$\mathrm{R} \$ 4.000 .000,00$

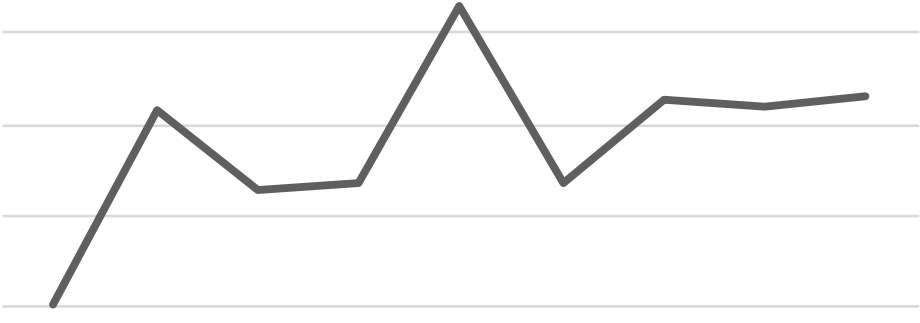

$\mathrm{R} \$ 2.000 .000,00$

$\mathrm{R} \$ 0,00$

Fonte: Elaboração própria.

\section{RESULTADOS ECONOMÉTRICOS}

Como enfatizado na seção anterior, foram utilizadas de 2 a 4 defasagens no intuito de demonstrar a robustez do modelo econométrico estimado, e pelo fato de a literatura apontar que o aumento no número de defasagens eleva a eficiência do estimador. Além disso, a variável explicada foi utilizada com 1 defasagem como variável explicativa, a fim de verificar o componente inercial da criminalidade. Por fim, o modelo foi estimado com robustez dos erros-padrão para corrigir a heterocedasticidade verificada, sendo seus resultados apresentados na Tabela 3.

Inicialmente, observa-se que as variáveis que representam o efeito deterrenceapresentam efeitos distintos sobre as taxas de homicídios. A variável que denota os gastos com policiamento não foi estatisticamente significativa, ao contrário daquela que representa os gastos com o sistema judiciário, que foi significativa, no entanto, o sinal do coeficiente estimado foi positivo e seu valor relativamente pequeno. Tais resultados sugerem que os gastos com segurança pública possuem questionável capacidade observável em dissuadir a consumação de homicídios.

No geral, os resultados relativamente modestos verificados do efeito deterrence no presente estudo possuem respaldo na literatura. Saridakis e Spengler (2012) afirmam que variáveis de dissuasão possuem pouco ou nenhum efeito sobre crimes violentos contra a pessoa, pois elas tendem a impactar primordialmente sobre a propensão ao risco, vide o estudo seminal de Becker (1968). Logo, o efeito deterrence possui maior significância na determinação de crimes contra o patrimônio, ou seja, crimes de cunho econômico, como apresentado por Wolpin (1978), Entorf e Spengler (2000), Cherry e List (2002) e Saridakis (2004). 
TABELA 3

\begin{tabular}{|c|c|}
\hline \multicolumn{2}{|l|}{ Resultados econométricos } \\
\hline Variável & Coeficiente \\
\hline fator inercial & $0.5965^{* * *}$ \\
\hline gasto_pol & $0.0007^{\text {NS }}$ \\
\hline gasto_jus & $0.0005^{*}$ \\
\hline educ & $-0.0295^{* * *}$ \\
\hline grau_urba & $0.0017^{\text {NS }}$ \\
\hline lrenda & $0.0102 *$ \\
\hline hom_jov_negro & $-0.0166^{N S}$ \\
\hline Constante & $1.6752 * *$ \\
\hline \multicolumn{2}{|c|}{$\begin{array}{r}\text { Notas: *** significativo a 1\%; ** significativo a 5\%; * significativo a 10\%; NS não significativo. } \\
\text { Defasagem dos instrumentos: } 2 \text { a } 4 \text { lags. }\end{array}$} \\
\hline
\end{tabular}

Quanto ao sinal positivo da variável que representa os gastos com o sistema judiciário, imagina-se, a princípio, que esse resultado é oposto ao esperado. Porém, ele vai ao encontro da literatura a partir de três fatores.

Em primeiro lugar, segundo Piliavin et al. (1986), deve-se considerar a relação endógena entre a ocorrência de homicídios e as variáveis que representam o efeito deterrence. Nesse sentido, em uma unidade da federação com elevadas taxas de homicídio, poderá ocorrer aumento nos gastos com o sistema judiciário para que se possa operacionalizar todas essas ocorrências. Ou seja, o aumento dos gastos em justiça é resultado dos custos mais elevados para que os criminosos sejam punidos.

Além disso, Levitt (2002) aponta que a condenação de indivíduos em uma determinada modalidade de crime pode fazer com que a ocorrência de outros tipos de crimes aumente. Dessa forma, os gastos com o sistema judiciário, aqui utilizados como proxies para o bom funcionamento do sistema de justiça, podem estar concentrados em processos judiciais relativos a outros tipos de crimes, como tráfico de drogas ${ }^{5}$ ou corrupção ${ }^{6}$, por exemplo, cujas ocorrências são elevadas no país. Assim, supõe-se que a capacidade do sistema judiciário em julgar e condenar indivíduos que cometeram homicídios é debilitada pela alocação dos gastos desproporcionalmente sobre outras modalidades de crimes.

Por fim, deve-se considerar a influência do efeito da impunidade sobre os indivíduos. No Brasil, segundo o Mapa da Violência de 2011 (WAISELFISZ, 2011), apenas 8\% do total de homicídios são apurados, isto é, em apenas 8 de 100 casos de homicídios os criminosos são identificados e condenados. O simples aumento dos gastos com o sistema judiciário não implica, necessariamente, em uma boa alocação desses recursos, como argumentado acima. Assim, gastos mais elevados não são estritamente convertidos em condenações aos infratores, o que por sua vez gera sensação de impunidade na sociedade em geral, quando observa-se que os homicídios não resultam significativamente em punições mais severas para seus autores. Logo, a sensação de impunidade atua na diminuição dos riscos e dos custos em se delinquir, estimulando ou não exercendo efeito de coerção sobre os criminosos.

5 Ver Campos (2018).

6 Ver Pelizzo (2020) 
Com relação às demais variáveis de controle, o coeficiente estimado para o componente inercial das taxas de homicídios tem sinal positivo e significativo a 1\%. Este resultado demonstra a influência das taxas de homicídio em um ano sobre seus valores no ano seguinte. Tal fenômeno, assim como descrito por Piliavin et al. (1986), pode ser explicado pelo fato de que os indivíduos tendem a encarar os elevados níveis de crime do período passado como um indicativo da incapacidade das instituições em punir os agentes que escolhem delinquir, demonstrando a existência de baixos riscos em se optar pela atividade criminosa.

Por sua vez, a educação, mensurada como a proporção da população economicamente ativa (PEA) que possui pelo menos ensino médio completo, apresentou sinal negativo e estatisticamente significativo, o que vai ao encontro da teoria da escolha racional preconizada por Becker (1968). Nesse caso, a escolaridade é compreendida como um elemento de fomento à produtividade dos indivíduos. Como exposto pelo autor, o maior nível de escolaridade resulta em maiores retornos aos agentes em suas atividades formais, aumentando a utilidade de não cometer crimes, o que tenderia a reduzir o nível de criminalidade. Além disso, como observado por Ehrlich (1975), a educação é peça-chave para o aumento do custo moral de se delinquir. Kume (2004), Araújo Júnior e Fajnzylber (2000) encontram resultados similares.

Assim como teorizado por Becker (1968) e corroborado por Araújo Júnior e Fajnzylber (2000) e Santos (2009), a variável que mensura a renda pode apresentar resultados ambíguos. Por um lado, o nível de renda mais elevado advindo do trabalho formal pode aumentar a utilidade do indivíduo em não cometer crimes, fazendo com que este opte por permanecer no mercado legal, o que poderia repercutir em impacto negativo sobre a criminalidade, assim como demonstrado por Cerqueira e Lobão (2003). Por outro lado, de acordo com Araújo Júnior e Fajnzylber (2001), o maior nível de renda pode acarretar em uma taxa mais elevada de crimes, uma vez que representa aumento do retorno esperado da atividade criminosa, como foi observado por Teixeira (2011), Mendonça (2013) e Kume (2004). No presente estudo, a variável que representa o nível de renda per capita das unidades federativas no período analisado apresentou resultado positivo e estatisticamente significativo. Desse modo, pode-se inferir que a renda mais elevada é capaz de aumentar o pay-off obtido da atividade criminosa, o que por sua vez estimula os agentes infratores a delinquir.

A literatura referente ao tema aponta que a variável que representa os homens jovens negros, protagonistas nas ocorrências de homicídios, se relaciona positivamente com as taxas de homicídios, assim como o grau de urbanização. Essas variáveis, entretanto, não foram estatisticamente significativas para a amostra e o período delimitados e para a metodologia utilizada.

\section{CONSIDERAÇÕES FINAIS}

As variáveis que compreendem efeitos dissuasórios (deterrence) representam fatores capazes de aumentar os custos dos indivíduos em prosseguir nas atividades criminosas, elevando seus riscos em serem delatados, indiciados ou presos. Assim, este estudo objetivou analisar o referido efeito deterrence, tendo como proxies os gastos públicos per capita com justiça e policiamento sobre as taxas de homicídio no Brasil durante o período 2005-2013.

No geral, os resultados encontrados não foram capazes de atestar a influência do efeito deterrence sobre as taxas de homicídio, vide a não significância do coeficiente estimado para a variável que representa os gastos 
com policiamento, indo ao encontro do que fora observado em outros estudos na literatura. Uma possível explicação está no fato de que o referido efeito está mais relacionado a crimes contra o patrimônio.

Além disso, o coeficiente estimado para os gastos com o sistema judiciário apresentou sinal positivo e valor reduzido, denotando sua relação endógena com as taxas de homicídio. Logo, em unidades da federação com taxas de homicídios mais elevadas, os gastos para que os criminosos sejam julgados e condenados são mais altos.

A partir dos resultados, salienta-se a necessidade de se formular políticas públicas de combate à criminalidade, que não visem somente aumentar os custos de punição aos criminosos. É necessário investir mais em educação, emprego, promoção da formalidade no mercado de trabalho, de modo a verificar resultados positivos e mais robustos no longo prazo em termos de diminuição da criminalidade.

Por fim, recomenda-se o desenvolvimento de futuras pesquisas, que contemplem variáveis capazes de refletir o efeito deterrence com maior fidedignidade, como o número de policiais por 100 mil habitantes, as taxas de encarceramento, a quantidade de delegacias, o montante de gastos com iluminação pública e a quantidade de câmeras de vigilância, por exemplo; ou ainda que considerem um horizonte temporal mais elevado com o intuito de melhor analisar a dinâmica das variáveis em questão.

\section{REFERÊNCIAS BIBLIOGRÁFICAS}

ANWAR, S.; LOUGHRAN, T. A. Testing a Bayesian Learning Theory of Deterrence among Serious Juvenile Offenders. Criminology, v. 49, n. 3, 2011, p. 667-698.

ARAÚJO JÚNIOR, A. F. de; FAJNZYLBER, P. O que causa a criminalidade violenta no Brasil? Uma análise a partir do modelo econômico do crime: 1981 a 1996. Textos para Discussão - Cedeplar, n. 162, Universidade Federal de Minas Gerais, Cedeplar-UFMG, 2001.

ARAÚJO JÚNIOR, A. F. de; FAJNZYLBER, P. Crime e economia: um estudo das microrregiões mineiras. Revista Econômica do Nordeste, v. 31, número especial, 2000, p. 630-659.

ARELLANO, M.; BOND, S. Some Tests of Specification for Panel Data: Monte Carlo Evidence and an Application to Employment Equations. The Review of Economic Studies, v. 58, n. 2, abr. 1991, p. 277-297.

BECKER, G. S. Crime and punishment: An economic approach. In: FIELDING, N. G.; CLARKE, A.; WITT, R. (Orgs.). The economic dimensions of crime. Londres: Palgrave Macmillan, 1968, p. 13-68.

BECKER, K. L.; KASSOUF, A. L. Uma análise do efeito dos gastos públicos em educação sobre a criminalidade no Brasil. Revista Economia e Sociedade, v. 26, n. 1, 2017, p. 215-242.

BELL, B.; JAITMAN, L.; MACHIN, S. Crime deterrence: evidence from the London 2011 riots. The Economic Journals, v. 124, maio. 2014, p. 480-506.

BRAGA, A. A.; WEISBURD, D.; TURCHAN, B. Focused deterrence strategies and crime control: An updated systematic review and metaDanalysis of the empirical evidence. Criminology \& Public Policy, v. 17, n. 1, 2018, p. 205-250.

BRASIL. Decreto-Lei 2.848, de 07 de dezembro de 1940. Código Penal. Diário Oficial da União, Rio de Janeiro, 31 dez. 1940. 
CAMPOS, M. da S. O Novo nem sempre vem: lei de drogas e encarceramento no Brasil. Boletim de Análise Político-Institucional - Ipea, n. 18, dez. 2018.

CASTANHEIRA JÚNIOR, F. G. Gasto público em segurança e criminalidade: uma análise de eficácia e eficiência. 2011. Dissertação (Mestrado em Ciências Econômicas) - Universidade do Estado do Rio de Janeiro (UERJ), Rio de Janeiro-RJ, 2011.

CERQUEIRA, D. Custo de Bem-estar da Violência e Criminalidade no Brasil. In: Anuário Brasileiro de Segurança Pública 2017. São Paulo: Fórum Brasileiro de Segurança Pública, 2017.

CERQUEIRA, D.; LOBÃO, W. Condicionantes sociais, poder de polícia e o setor de produção criminal. Texto para Discussão - Ipea, n. 957, Rio de Janeiro, jun. 2003.

CERQUEIRA, D. R. de C. Causas e consequências do crime no Brasil. 2014. Tese (Doutorado em Economia) - Pontifícia Universidade Católica do Rio de Janeiro (PUC-RJ), Rio de Janeiro, 2014.

CHALFIN, A.; MCCRARY, J. Criminal Deterrence: A Review of the Literature. Journal of Economic Literature, v. 55, n. 1, 2017, p. 5-48.

CHERRY, T. L.; LIST, J. A. Aggregation bias in the economic model of crime. Economics Letters, v. 75, n. 1, 2002, p. 81-86.

CORMAN, H.; MOCAN, H. N. A Time-Series Analysis of Crime, Deterrence and Drug Abuse in New York City. American Economic Review, v. 90, n. 3, 2000, p. 584-604.

EHRLICH, I. The deterrent effect of capital punishment: A question of life and death. The American Economic Review, v. 65, n. 3, jun. 1975, p. 397-417.

ENTORF, H.; SPLENGER, H. Criminality, Social Cohesion and Economic Performance. Würzburg Economic Paper, n. 22, 2000, p. 1-25.

FBSP - FÓRUM BRASILEIRO DE SEGURANÇA PÚBLICA. Anuário Brasileiro de Segurança Pública: $1^{\circledR}$ a $8^{a}$ edição. Disponível em: https://Forumseguranca.org.br/anuario-brasileiro-seguranca-publica/. Acesso em: 15 jun. 2019.

FURTADO, G. M. Aplicação da economia do crime no Brasil. 2007. Dissertação (Mestrado Profissional em Economia) - Faculdade IBMEC São Paulo, São Paulo, 2007.

GOULD, E.; WEINBERG, B.; MUSTARD, D. Crime rates and local labor market opportunities in the United States: 1979-1997. The Review of Economics and Statistics, v. 84, n. 1, 2002, p. 45-61.

IBGE - INSTITUTO BRASILEIRO DE GEOGRAFIA E ESTATÍ́STICA. Pesquisa Nacional por Amostra de Domicílios (Pnad): 2005 a 2013. Disponível em: https://www.ibge.gov.br/estatisticas/sociais/populacao/9127-pesquisanacional-por-amostra-de-domicilios.html?edicao=18338t=publicacoes. Acesso em: 12 jun. 2019.

IPEA - INSTITUTO DE PESQUISA ECONÔMICA APLICADA. Reincidência criminal no Brasil. Relatório de Pesquisa - Ipea, Rio de Janeiro, 2015.

IPEA - INSTITUTO DE PESQUISA ECONÔMICA APLICADA; FBSP - FÓRUM BRASILEIRO DE SEGURANÇA PÚBLICA. Atlas da Violência 2017. Rio de Janeiro, 2017.

IPEA - INSTITUTO DE PESQUISA ECONÔMICA APLICADA; FBSP - FÓRUM BRASILEIRO DE SEGURANÇA PÚBLICA. Atlas da Violência 2018. Rio de Janeiro, 2018. IPEA - INSTITUTO DE PESQUISA ECONÔMICA APLICADA; FBSP - FÓRUM BRASILEIRO DE SEGURANÇA PÚBLICA. Atlas da Violência 2019. Rio de Janeiro, 2019. JOHNSON, R.; RAPHAEL, S. How much crime reduction does the marginal prisoner buy?. The Journal of Law and Economics, v. 55, n. 2, 2012, p. 275-310. 
KLECK, G.; BARNES, J. C. Do More Police Lead to More Crime Deterrence? Crime \& Deliquency, v. 60, $n$. 5, 2014, p. 716-738.

KUME, L. Uma estimativa dos determinantes da taxa de criminalidade brasileira: uma aplicação em painel dinâmico. Anais... $32^{\circ}$ Encontro Nacional de Economia. Promovido pela Anpec, em João Pessoa-PB, dez. 2004.

LEE, D. S.; MCCRARY, J. The deterrence effect of prison: Dynamic theory and evidence. Emerald Publishing Limited, 2017, p. 73-146.

LEUNG, S. F. Dynamic Deterrence Theory. Economica, v. 62, n. 245, fev. 1995, p. 65-87.

LEVITT, S. D. Using electoral cycles in police hiring to estimate the effects of police on crime: Reply. American Economic Review, v. 92, n. 4, 2002, p. 1244-1250.

LINS, G. de O. A.; MONTES, G. C. Evidências para os efeitos de Deterrence, desenvolvimento socioeconômico e revanche policial sobre a violência nos municípios do Rio de Janeiro. Anais... $45^{\circ}$ Encontro Nacional de Economia. Promovido pela Anpec, Rio Grande do Norte-RS, dez. 2017.

LOBO, L. F.; FERNANDEZ-CARRERA, J. A criminalidade na região metropolitana de Salvador. Análise Econômica, v. 23, n. 44, 2005.

LOUREIRO, A. O. F.; CARVALHO JÚNIOR, J. R. de A. O impacto dos gastos públicos sobre a criminalidade no Brasil. In: HERMANNS, K.; ARRAES, R. A. (Orgs.). Desigualdades e Políticas Regionais. Fortaleza: Fundação Konrad Adenauer, 2007, p. 165-193.

MACHADO, J. B. de B.; SACHSIDA, A.; MENDONÇA, M. J. C. de. Abertura comercial e inflação: uma análise para dados em painel. Estudos Econômicos, São Paulo, v. 35, n. 3, 2005, p. 547-567.

MENDONÇA, M. J. C. de. Criminalidade e violência no Brasil: uma abordagem teórica e empírica. Revista Brasileira de Economia de Empresas, v. 2, n. 1, 2013, p. 1-17.

MENDONÇA, M. J. C. de; SACHSIDA, A.; LOUREIRO, P. R. A. Criminalidade e desigualdade social no Brasil. Texto para Discussão - Ipea, n. 967, Rio de Janeiro: Ipea, 2003.

PEZZIN, L. E.; MACEDO, R. B. M. Criminalidade urbana e crise econômica: o caso de São Paulo. São Paulo: Instituto de Pesquisas Econômicas/USP, 1987.

PELIZZO, R. Corruption Perception Index 2019. Transparency International, 2020.

PILIAVIN, I.; GARTNER, R.; THORNTON, C.; MATSUEDA, R. Crime, Deterrence, and Rational Choice. American Sociological Review, v. 51, n. 1, 1986, p. 101-119.

SANTOS, M. J. dos. Dinâmica Temporal da Criminalidade: Mais evidências sobre o "Efeito Inércia" nas taxas de crimes letais no estados brasileiros. Revista EconomiA, Brasília-DF, v. 10, n. 1, jan./abr. 2009, p. 169-194.

SANTOS, M. J. dos; KASSOUF, A. L. Estudos econômicos das causas da criminalidade no Brasil: evidências e controvérsias. Revista EconomiA, Brasília-DF, v. 9, n. 2, 2008, p. 343-372.

SARIDAKIS, G. Violent crime in the United States of America: A time-series analysis between 19602000. European Journal of Law and Economics, v. 18, n. 2, 2004, p. 203-221.

SARIDAKIS, G.; SPENGLER, H. Crime, deterrence and unemployment in Greece: A panel data approach. The Social Science Journal, v. 49, n. 2, 2012, p. 167-174.

SCHELL-BUSEY, N.; SIMPSON, S. S.; RORIE, M.; ALPER, M. What Works? A Systematic Review of Corporate Crime Deterrence. Criminology \& Public Policy, v. 15, n. 2, 2016, p. 387-416. 
SHERMAN, L. W.; WEISBURD, D. General deterrent effects of police patrol in crime "hot spots": A randomized, controlled trial. Justice quarterly, v. 12, n. 4, 1995, p. 625-648.

SOARES, S. S. D. Educação: um escudo contra o homicídio?. Texto para Discussão - Ipea, n. 1298, BrasíliaDF, ago. 2007.

SULIANO, D. C.; OLIVEIRA, J. L. de. Polícia reduz crime? Um estudo de caso na RMF do Ceará. Texto para Discussão - Ipece, n. 88, Fortaleza-CE, dez. 2010.

TEIXEIRA, E. C. Dois ensaios acerca da relação entre criminalidade e educação. 2011. Tese (Doutorado em Economia Aplicada) - Escola Superior de Agricultura Luiz de Queiroz, Universidade de São Paulo (Esalq/USP), Piracicaba-SP, 2011.

VIEIRA, F. V.; AVELLAR, A. P. M. de; VERÍSSIMO, M. P. Indústria e crescimento: análise de painel. Núcleo de Economia Regional e Urbana da Universidade de São Paulo, São Paulo: TD Neurus, jun. 2013.

WAISELFISZ, J. J. Mapa da violência 2011: os jovens do Brasil. Instituto Sangari \& Ministério da Justiça, 2011. WOLPIN, K. I. An economic analysis of crime and punishment in England and Wales, 1894-1967. Journal of Political Economy, v. 86, ก. 5, 1978, p. 815-840. 


\section{ANEXO 1}

\section{GRÁFICO 4}

Taxa de Homicídios na região Norte durante o período 2005-2013

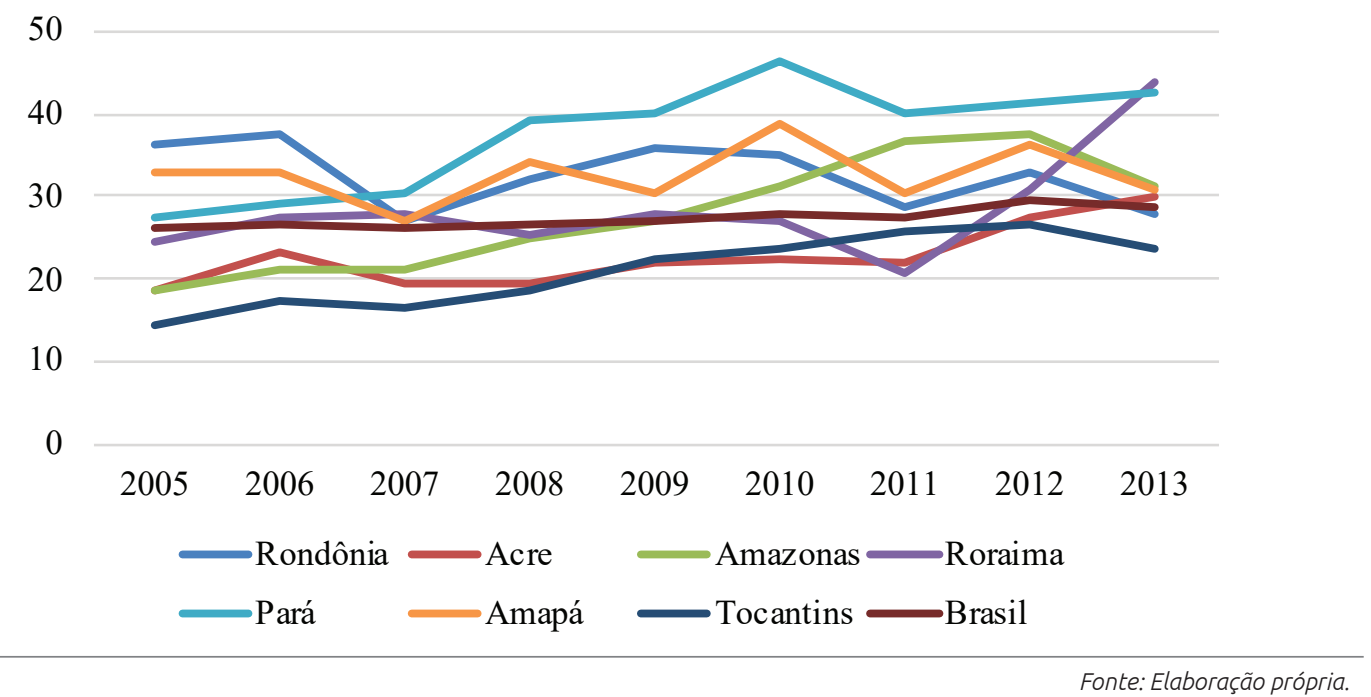

\section{GRÁFICO 5}

Taxa de Homicídios na região Nordeste durante o período 2005-2013

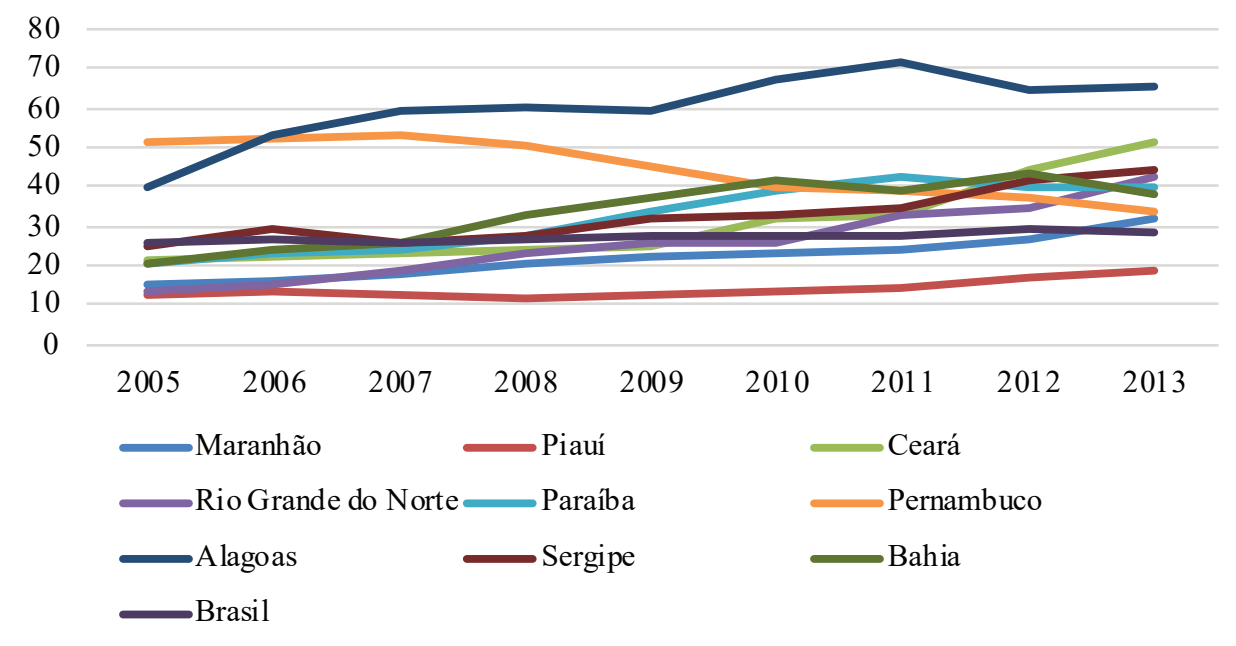

Fonte: Elaboração própria. 


\section{GRÁFICO 6}

Taxa de Homicídios na região Sudeste durante o período 2005-2013

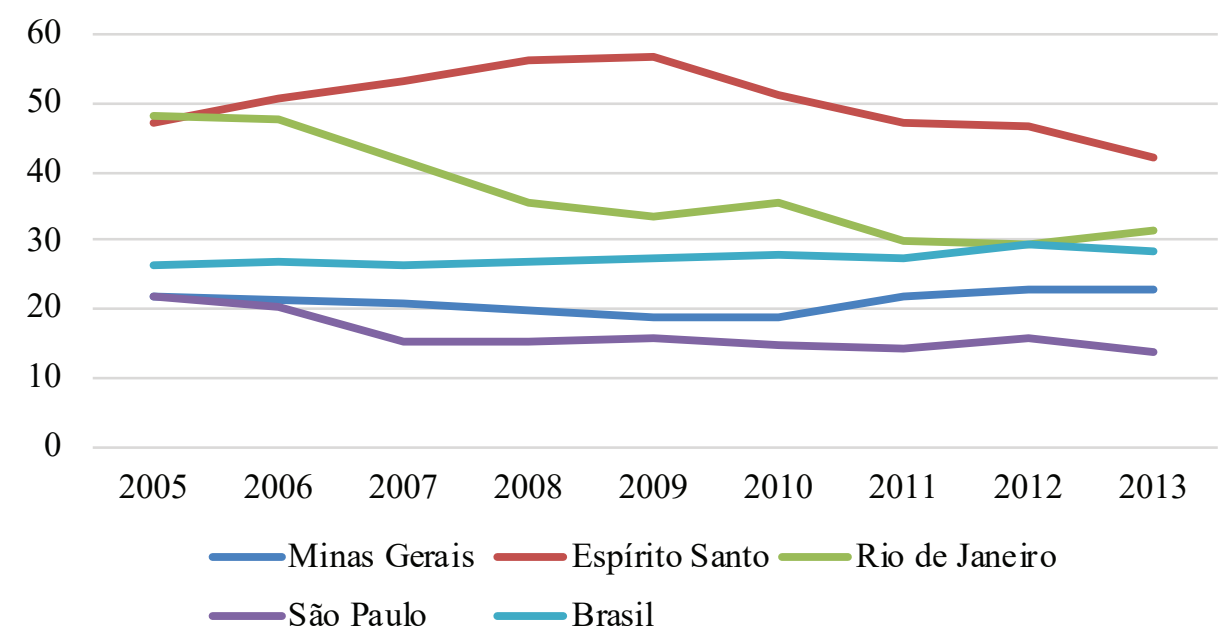

\section{GRÁFICO 7}

Taxa de Homicídios na região Centro-Oeste durante o período 2005-2013

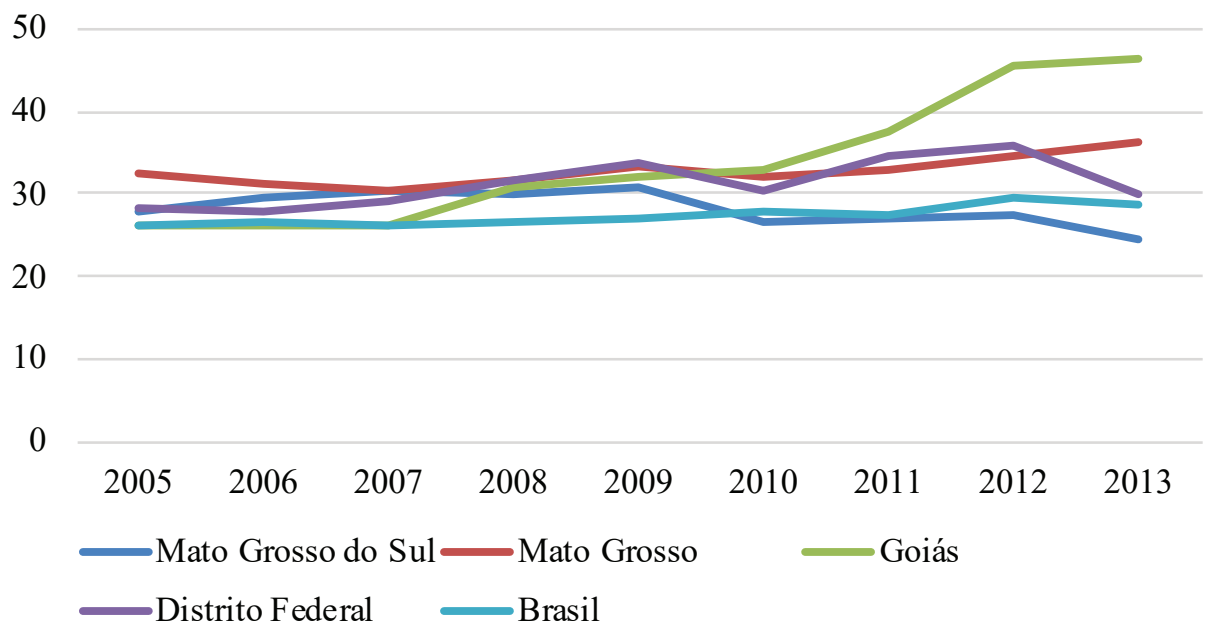




\section{GRÁFICO 8}

Taxa de Homicídios na região Sul durante o período 2005-2013

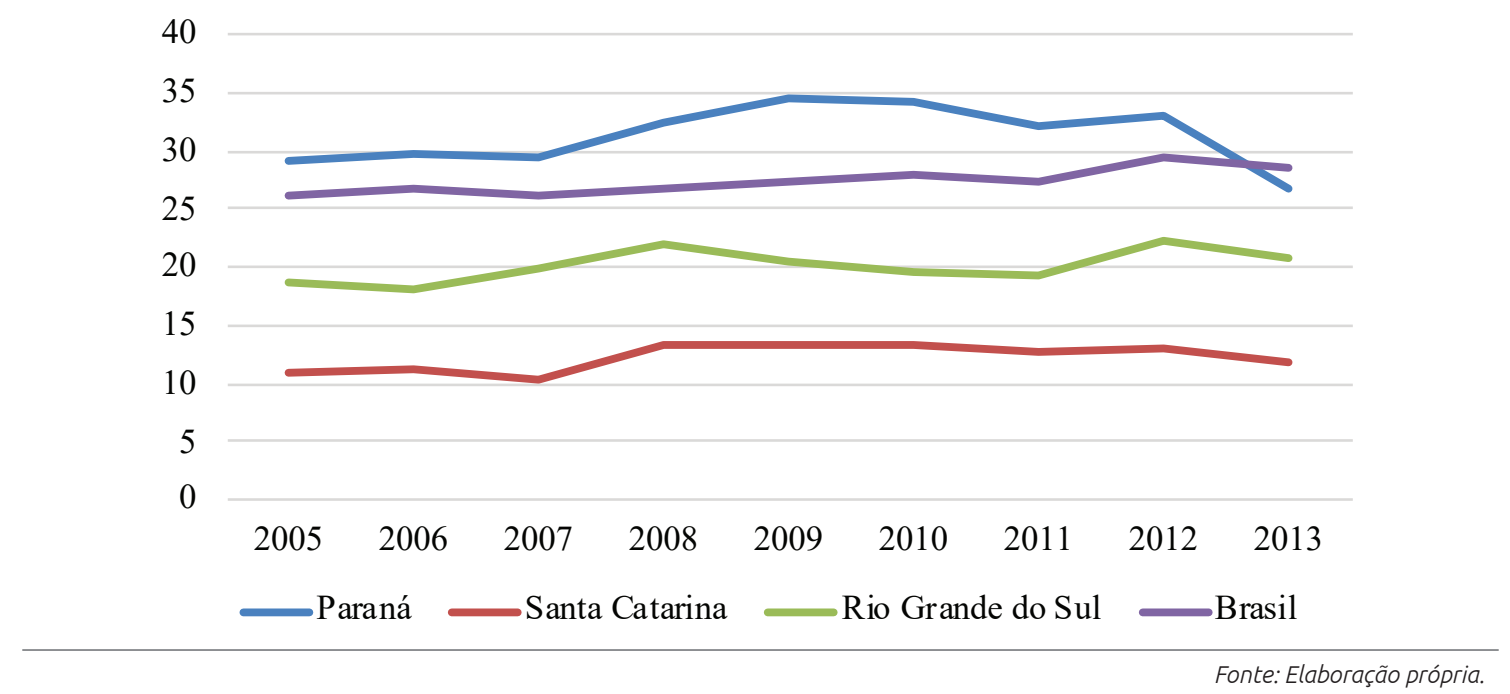




\section{ANEXO 2}

\section{GRÁFICO 9}

Gastos com Justiça por 100 mil habitantes na região Norte durante o período 2005-2013

$\mathrm{R} \$ 50.000 .000,00$ $\mathrm{R} \$ 45.000 .000,00$ $\mathrm{R} \$ 40.000 .000,00$ $\mathrm{R} \$ 35.000 .000,00$ $\mathrm{R} \$ 30.000 .000,00$ $\mathrm{R} \$ 25.000 .000,00$ $\mathrm{R} \$ 20.000 .000,00$ $\mathrm{R} \$ 15.000 .000,00$ $\mathrm{R} \$ 10.000 .000,00$ $\mathrm{R} \$ 5.000 .000,00$ $\mathrm{R} \$-$

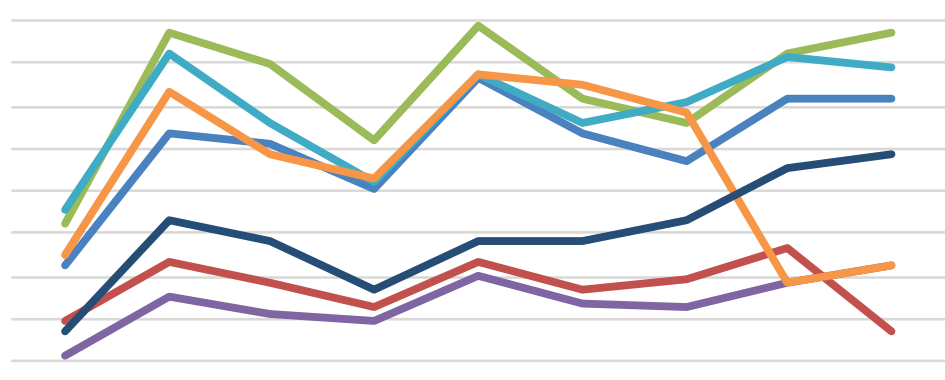

$2005 \quad 2006 \quad 2007 \quad 2008 \quad 2009 \quad 2010 \quad 2011 \quad 2012 \quad 2013$

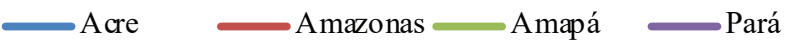

Rondônia Roraima $\longrightarrow$ Tocantins

\section{GRÁFICO 10}

Gastos com Justiça por 100 mil habitantes na região Nordeste durante o período 2005-2013

$\mathrm{R} \$ 30.000 .000,00$
$\mathrm{R} \$ 25.000 .000,00$
$\mathrm{R} \$ 20.000 .000,00$
$\mathrm{R} \$ 15.000 .000,00$
$\mathrm{R} \$ 10.000 .000,00$
$\mathrm{R} \$ 5.000 .000,00$

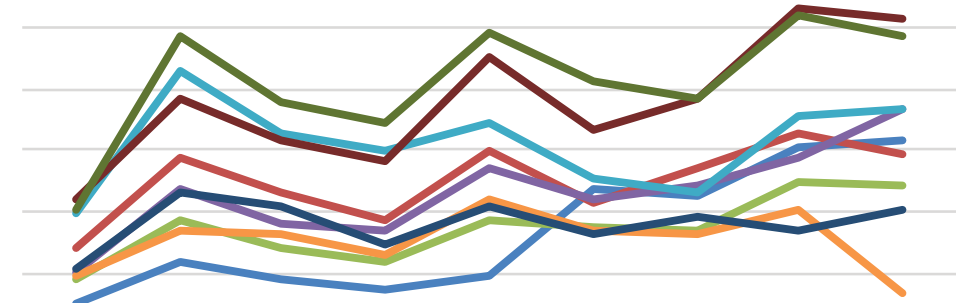

$\mathrm{R} \$$ -

$$
\begin{array}{lllllllll}
2005 & 2006 & 2007 & 2008 & 2009 & 2010 & 2011 & 2012 & 2013
\end{array}
$$

\begin{tabular}{|c|c|c|}
\hline Alagoas & Bahia & Ceará \\
\hline Maranhão & $\longrightarrow$ Paraíba & Pernambuco \\
\hline —Piauí & $\longrightarrow$ Rio Gra & Sergipe \\
\hline
\end{tabular}

Fonte: Elaboração própria. 


\section{GRÁFICO 11}

Gastos com Justiça por 100 mil habitantes na região Sudeste durante o período 2005-2013

\begin{abstract}
$\mathrm{R} \$ 45.000 .000,00$ $\mathrm{R} \$ 40.000 .000,00$

$\mathrm{R} \$ 35.000 .000,00$

$\mathrm{R} \$ 30.000 .000,00$ $\mathrm{R} \$ 25.000 .000,00$ $\mathrm{R} \$ 20.000 .000,00$ $\mathrm{R} \$ 15.000 .000,00$ $\mathrm{R} \$ 10.000 .000,00$ $\mathrm{R} \$ 5.000 .000,00$
\end{abstract}

$\mathrm{R} \$-$

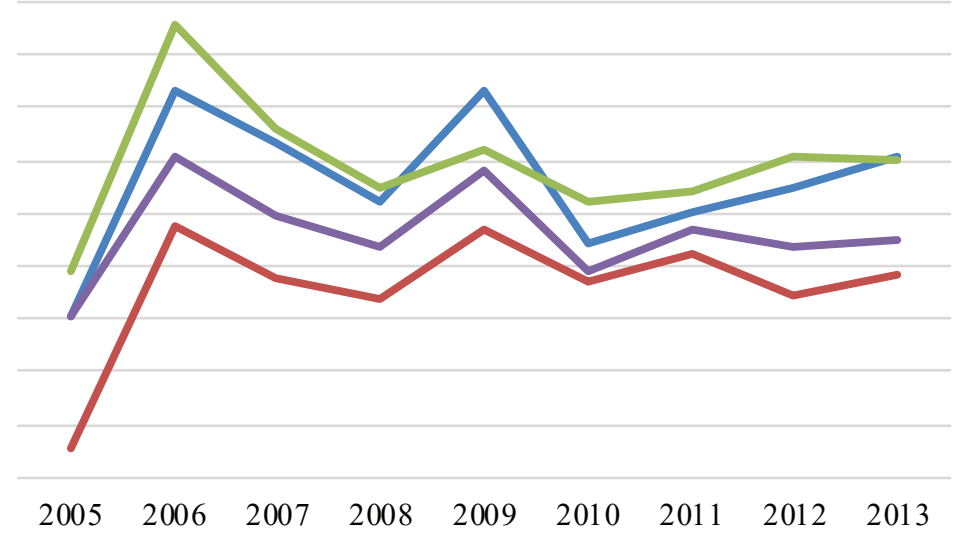

$\longrightarrow$ Espírito Santo $\longrightarrow$ Minas Gerais $\longrightarrow$ Rio de Janeiro $\longrightarrow$ São Paulo

\section{GRÁFICO 12}

Gastos com Justiça por 100 mil habitantes na região Centro-Oeste durante o período 2005-2013

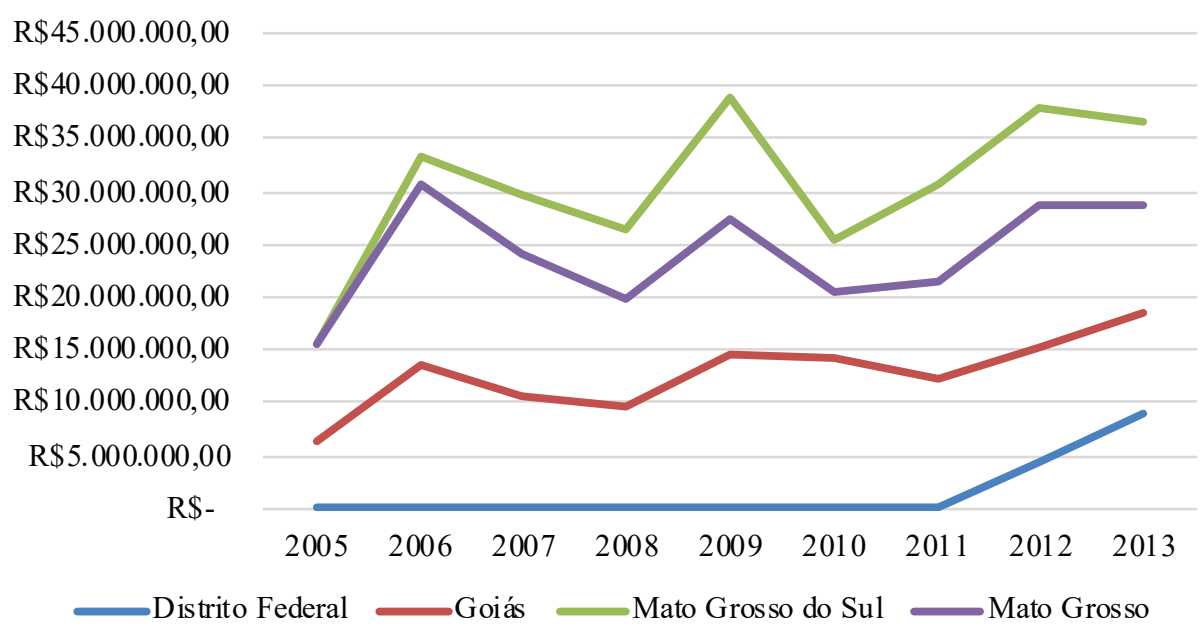




\section{GRÁFICO 13}

Gastos com Justiça por 100 mil habitantes na região Sul durante o período 2005-2013

$\mathrm{R} \$ 40.000 .000,00$

$\mathrm{R} \$ 35.000 .000,00$

$\mathrm{R} \$ 30.000 .000,00$

$\mathrm{R} \$ 25.000 .000,00$

$\mathrm{R} \$ 20.000 .000,00$

$\mathrm{R} \$ 15.000 .000,00$

$\mathrm{R} \$ 10.000 .000,00$

$\mathrm{R} \$ 5.000 .000,00$

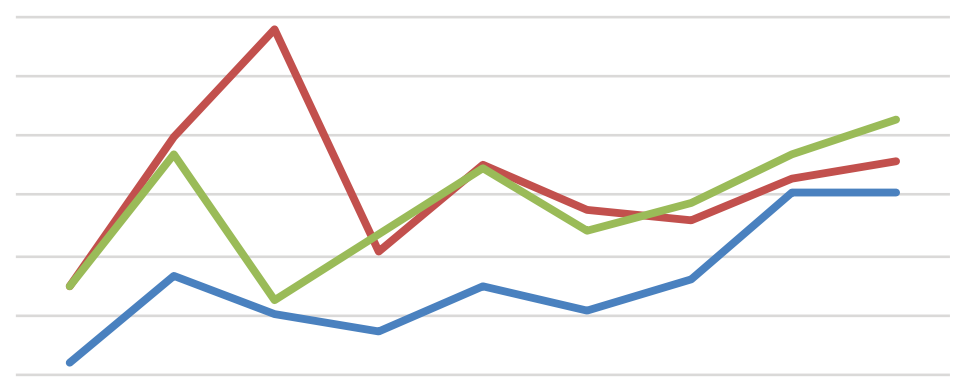

$\mathrm{R} \$-$

$\begin{array}{lllllllll}2005 & 2006 & 2007 & 2008 & 2009 & 2010 & 2011 & 2012 & 2013\end{array}$

Paraná —Rio Grande do Sul —Santa Catarina 


\section{ANEXO 3}

\section{GRÁFICO 14}

Gastos com Policiamento por 100 mil habitantes na região Norte durante o período 2005-2013

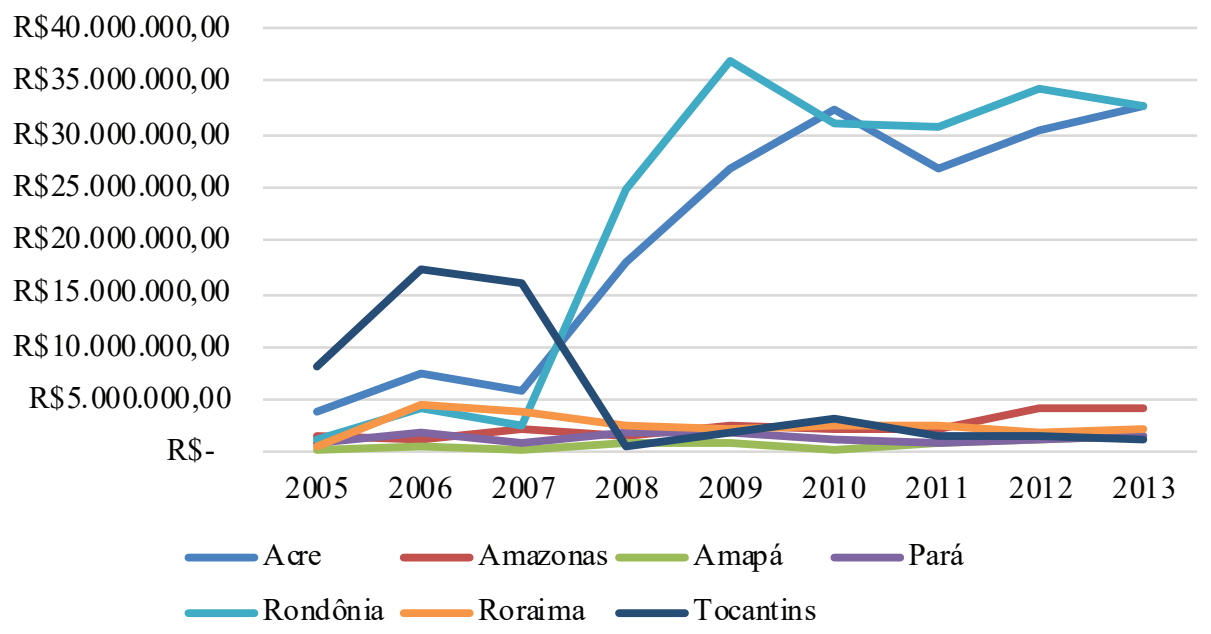

Fonte: Elaboração própria.

\section{GRÁFICO 15}

Gastos com Policiamento por 100 mil habitantes na região Nordeste durante o período 2005-2013

$\mathrm{R} \$ 25.000 .000,00$

$\mathrm{R} \$ 20.000 .000,00$

$\mathrm{R} \$ 15.000 .000,00$

$\mathrm{R} \$ 10.000 .000,00$

$\mathrm{R} \$ 5.000 .000,00$

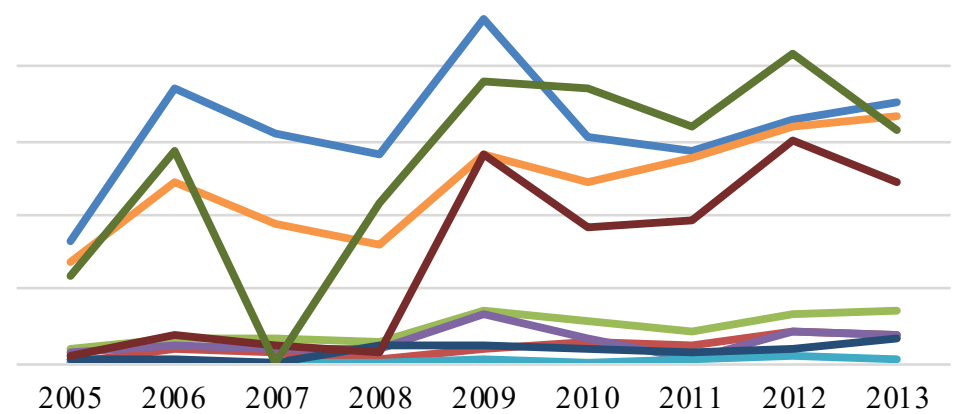

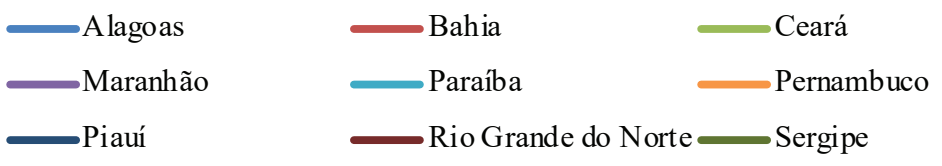




\section{GRÁFICO 16}

Gastos com Policiamento por 100 mil habitantes na região Sudeste durante o período 2005-2013

$\mathrm{R} \$ 35.000 .000,00$

$\mathrm{R} \$ 30.000 .000,00$

$\mathrm{R} \$ 25.000 .000,00$

$\mathrm{R} \$ 20.000 .000,00$

$\mathrm{R} \$ 15.000 .000,00$

$\mathrm{R} \$ 10.000 .000,00$

$\mathrm{R} \$ 5.000 .000,00$

RS-

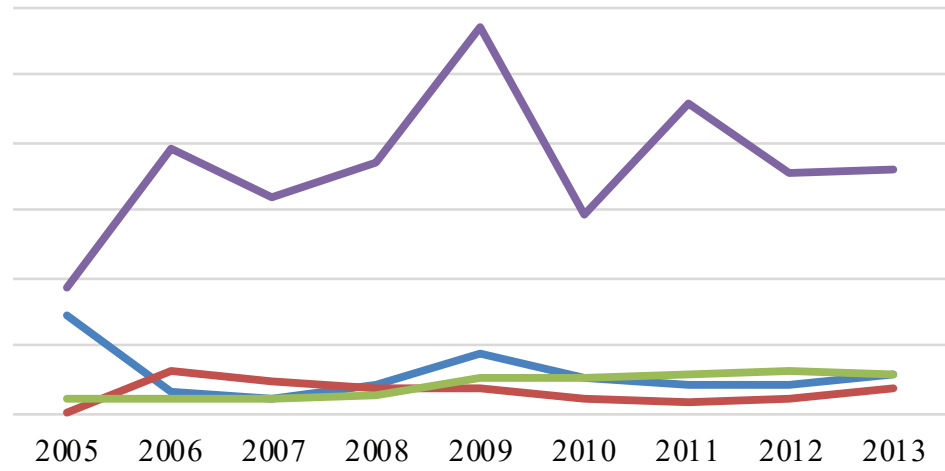

Espírito Santo —Minas Gerais $\longrightarrow$ Rio de Janeiro $\longrightarrow$ São Paulo

Fonte: Elaboração própria

\section{GRÁFICO 17}

\section{Gastos com Policiamento por 100 mil habitantes na região Centro-Oeste durante o período 2005-2013}

$\mathrm{R} \$ 40.000 .000,00$

$\mathrm{R} \$ 35.000 .000,00$

$\mathrm{R} \$ 30.000 .000,00$

$\mathrm{R} \$ 25.000 .000,00$

$\mathrm{R} \$ 20.000 .000,00$

$\mathrm{R} \$ 15.000 .000,00$

$\mathrm{R} \$ 10.000 .000,00$

$\mathrm{R} \$ 5.000 .000,00$

R\$-
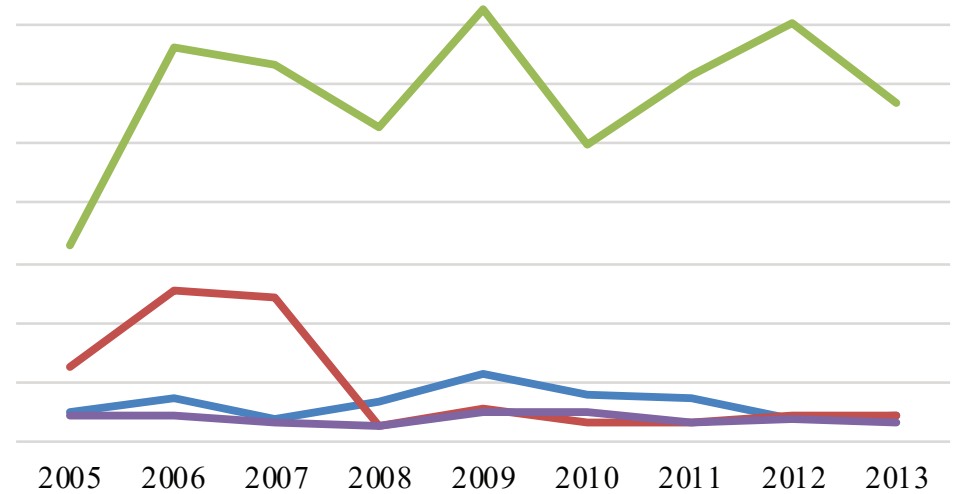

Distrito Federal Goiás Mato Grosso do Sul

Mato Grosso 


\section{GRÁFICO 18}

Gastos com Policiamento por 100 mil habitantes na região Sul durante o período 2005-2013

$\mathrm{R} \$ 25.000 .000,00$

$\mathrm{R} \$ 20.000 .000,00$

$\mathrm{R} \$ 15.000 .000,00$

$\mathrm{R} \$ 10.000 .000,00$

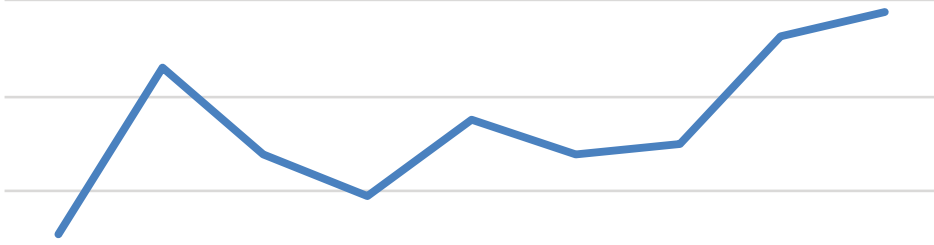

$\mathrm{R} \$ 5.000 .000,00$

$\mathrm{R} \$-$

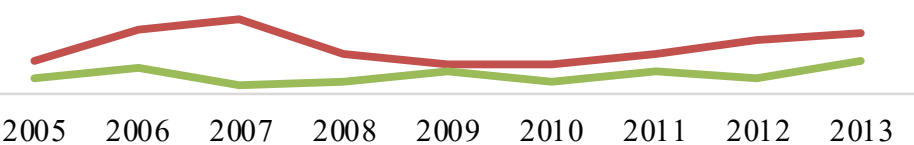

- Paraná —Rio Grande do Sul —Santa Catarina 